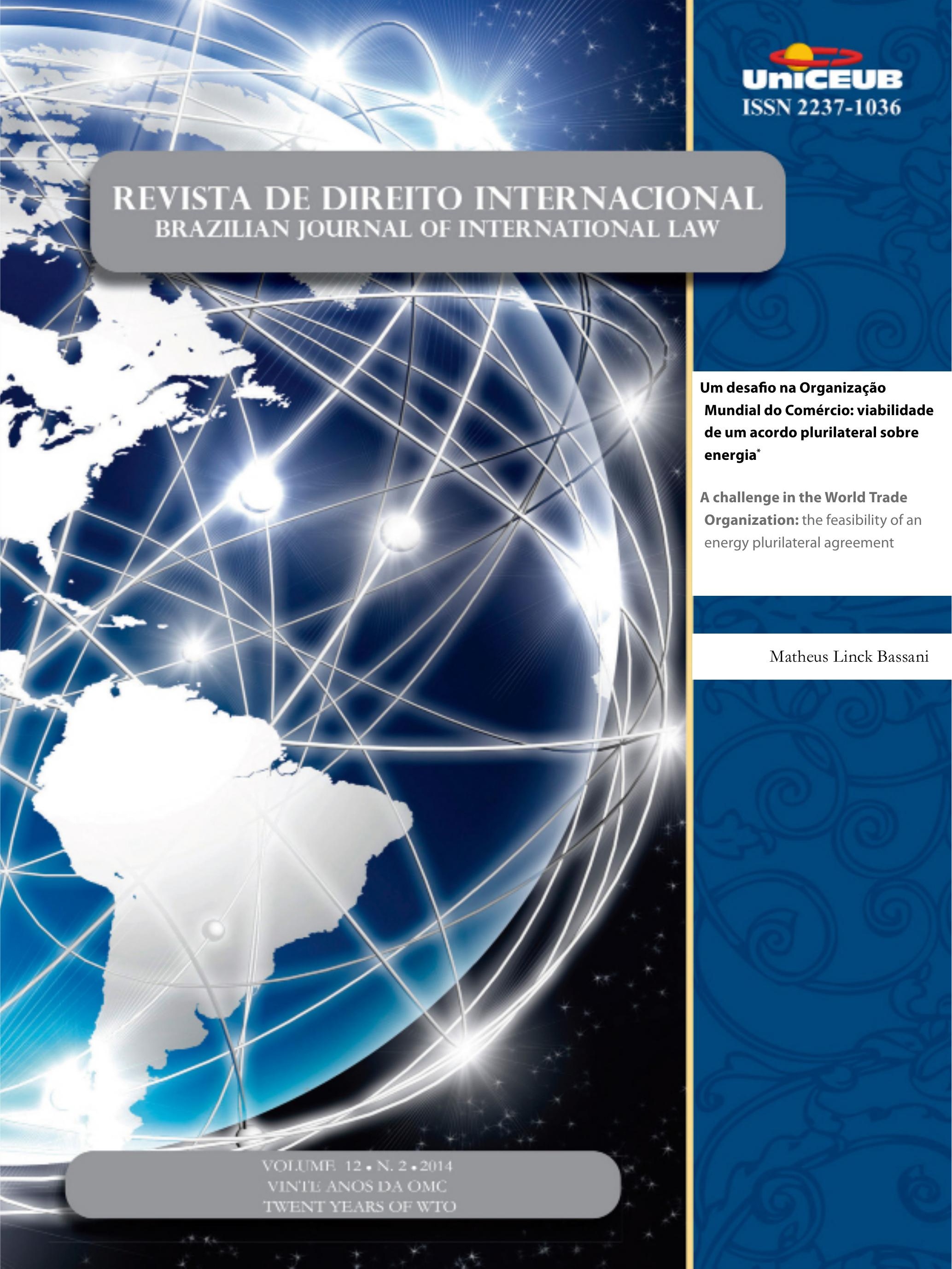


I. Crônicas

1. Crônicas da atualidade do Direito Internacional ......................................................16

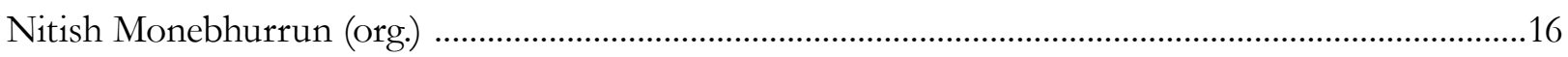

2.Decisões da Corte Internacional de Justiça e do Tribunal Internacional Sobre o Direito do Mar

Nitish Monebhurrun

José Eduardo Siqueira

3. Crônicas do direito internacional dos inVestimentos

Nitish Monebhurrun

\section{Os Vinte Anos dA OMC}

EXPORT CONTROLS AS INDUSTRIAL POLICY ON NATURAL RESOURCES: REGULATORY LIMITATIONS ON CHINA - RAW MATERIALS AND CHINA - RARE EARTHS CASES.

Gustavo Ferreira Ribeiro

O problema da espionagem econômica internacional: Seria a Organização Mundial do CoMÉRCIO O FORO ADEQUADO PARA SUA APRECIAÇÃO?

Humberto A.Vasconcelos Lima

Naiana Magrini Rodrigues Cunha

International Standards for Intellectual Property Rights Protection: a reflection on CLIMATE-FRIENDLY TECHNOLOGY TRANSFER.

Guihong Zhang

Jiani Jiang

Can Wang

Os vinte anos da OMC, suas conquistas e desafios: uma análise do Brasil e o Sistema de SoLUÇõES DE CONTROvÉRsias

Etiene M. Bosco Breviglieri

Luciano Meneguetti Pereira

A relação entre os tratados multilaterais ambientais e os acordos da OMC: é possível CONCILIAR O CONFLITO?

Fabio Costa Morosini,

Luisa Zuardi Niencheski 
Um desafio na Organização Mundial do Comércio: viabilidade de um aCordo plurilateral

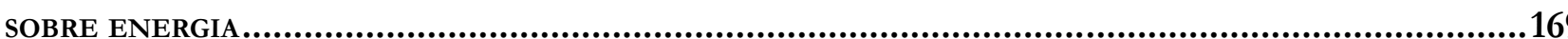

Matheus Linck Bassani

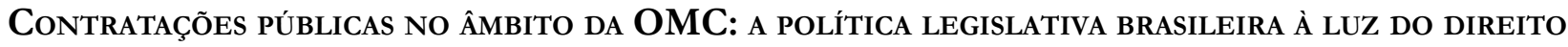
AO DESENVOLVIMENTO

André Jansen do Nascimento

Governança global e a Organização Mundial do Comércio: desafios impostos pelo novo MANDATO DE DESENVOLVIMENTO

Letícia de Souza Daibert

Ana Luísa Soares Peres

Vinte Anos de Crise para a África? Poder, Assimetrias e a Abordagem Liberal da OMC.....239 Igor Abdalla Medina de Souza

Os MECANISMOS DE INDUÇÃo AO CUMPRIMENTO NO ÂMBITO DA OMC

Fernando Lopes Ferraz Elias

A promoção de accountability na Organização Mundial do Comércio: uma Análise horiZONTAL E VERTICA

Celso Henrique Cadete de Figueiredo

LA OMC Y EL PROCESO DE GLOBALIZACION DE LA REGULACIÓN ALIMENTARIA

Maria Eugenia Marichal

O ACORDO GATS E SUA APLICAÇÃO AOS SERVIÇOS DO COMÉRCIO ELETRÔNICO

Gleisse Ribeiro Alves

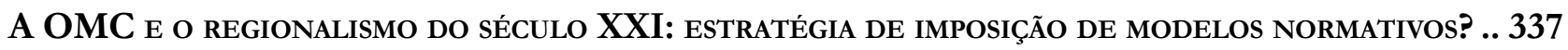
Camilla Capucio

A ORgANIZAÇÃo MUNDIAL do COMÉRCIO E A CHINA: DIREITO DE PROPRIEDADE E PROPRIEDADE INTELECTUAL NO PAÍS

Dos contenciosos NA OMC COM ENFOQUe EM RESTRIÇões Às EXPORTAÇÕES DA CHINA .363

Marco Antônio Alcântara Nascimento 
O redimensionamento da OMC no trato dos Acordos Comerciais Regionais

Alice Rocha da Silva

\section{Outros Temas}

Derechos Humanos EN LA REALIDAD ACTUAL: LA GLOBALIZACión Y El MUlTiCulturalismo

David Falcão

IMUNidAde de JURISDiÇão do Estado E REPARAÇão CIVIL PELA PRÁtica de TORTURA: O CASO ZaHRA

KaZEMI v. RepÚbliCa IsLÂMICA do Irã...

Patrícia Maria Lara Abreu

Rodrigo Otávio Bastos Silva Raposo

INTERREgional Organizations (IROS) IN EuROPE: NEW SUbJECTS OF CONTEMPORARY INTERNATIONAL LAW?

Davorin Lapas

A conexão entre os direitos humanos e a CorrupÇão.

Gabriela Alves Mendes Vieira

Marcelo Dias Varella

GRUPO DE SOCIEDADES: INSTRUMENTO JURÍDICO DE ORGANIZAÇÃo DA EMPRESA PLURISSOCIETÁRIA.....495

Daniel Amin Ferraz 


\title{
Um desafio na Organização Mundial do Comércio: viabilidade de um acordo plurilateral sobre energia*
}

\author{
A challenge in the World Trade Organization: the \\ feasibility of an energy plurilateral agreement
}

Matheus Linck Bassani**

\section{Resumo}

O presente artigo propõe um Acordo Plurilateral sobre o tema energético no âmbito da Organização Mundial do Comércio (OMC). Utiliza-se do método dedutivo e análise doutrinária, considerando-se relevante o resultado da pesquisa em razão da sua originalidade, especificidade e da abordagem temática, pouco explorada na área de Direito Internacional Público. Na primeira parte, identificam-se desafios, envolvendo o comércio de energia em face da incidência dos dispositivos normativos multilaterais, relacionados aos assuntos como tarifas, restrições, tributação, subsídios, trânsito, meio ambiente, investimentos e disputas relacionadas com energia, como os casos US - Reformulated Gasoline e os mais recentes com energia renovável. Na segunda parte, diante dos desafios apresentados, analisa-se a viabilidade de um Acordo Plurilateral sobre Energia no intuito de estabelecer melhor tratamento ao tema. Conclui-se que as normas da OMC poderiam ser atualizadas, mas as iniciativas são obstaculizadas pela regra do consenso. Um acordo plurilateral de energia para facilitar e acelerar os fluxos de energia de forma sustentável é uma solução mais viável, por facultar a adesão dos membros da própria OMC.

Palavras-chave: Energia. Organização Mundial do Comércio (OMC). Acordo Plurilateral. Multilateralismo. Energia Renovável. Sustentabilidade.

\section{Abstract}

This paper proposes an Energy Plurilateral Agreement in the World Trade Organization (WTO), through doctrine analysis and using the deductive method.

${ }^{*}$ Recebido em: 23.10 .2014 Aceito em: 18.11.2014

** Mestre em Direito pela Universidade Federal do Rio Grande do Sul - UFRGS. Pós-graduado nos Cursos de Especialização em Direito Tributário - IBET e no Curso de Especialização em Direito Público - ESMAFE/RS-IMED. Especialista em Droit Comparée et Européen, pela Universidade de Savoie, França. Pesquisador visitante do Center for Energy, Petroleum and Mineral Law and Policy - CEPMLP, na Universidade de Dundee, Reino Unido. Advogado. E-mail: matheusbassani@hotmail.com.
It evaluates major contribution of this research due its originality, specificity and thematic approach, underexplored in the area of Public International Law. In the first part, challenges involving energy trade are identified regarding multilateral rules relating to the matters as tariffs, restrictions, taxation, subsidies, transit, environment, investment and energy conflicts related as US - Reformulated Gasoline and the latest renewable energy cases. In the second part, the feasibility of an Energy Plurilateral Agreement is analyzed in order to establish the best treatment to the subject. The conclusion is that WTO rules could be updated, but initiatives are hampered by the consensus rule. An Energy Plurilateral Agreement to facilitate the energy trade flow in a sustainable way is a more viable solution by providing the faculty of accession by the members of the WTO.

Keywords: Energy. World Trade Organization (WTO). Plurilateral Agreement. Multilateralism. Renewable Energy. Sustainability. 


\section{Introdução}

Tratar de energia no comércio internacional requer uma análise precisa de um quadro multifacetado e complexo, por envolver diversas áreas, como meio ambiente e investimentos. Hoje, a Organização Mundial do Comércio (OMC) aborda o tema da energia como um bem, e, a partir dos entraves identificados, emerge a proposta para um Acordo específico.

Para se avaliar a confirmação ou não do problema trazido neste trabalho, ou seja, da viabilidade de se estabelecer um Acordo Plurilateral, utilizar-se-á do método dedutivo, mediante análise doutrinária, nacional e estrangeira, além de base de dados científicos.

A OMC regula o comércio de bens, serviços e propriedade intelectual, e, apesar de não incluir regras específicas ao comércio de energia, ela estabelece normas que são relevantes para o setor. Nesse artigo não serão abordados aspectos históricos, princípios gerais, e funcionamento estrutural da $\mathrm{OMC}$, em face da especificidade do tema. O intuito é ater-se somente aos aspectos que efetivamente impactam o comércio de energia.

A importância da organização vem crescendo em relação ao tema da energia, no momento que países estratégicos (produtores e consumidores) têm aderido ao sistema multilateral, como Equador, Oman, Arábia Saudita (2005), China (2001), Ucrânia (2008) e recentemente a Rússia, em 2012. Outros como Irã, Iraque, Cazaquistão, Líbia e Argélia ainda são observadores e negociam a acessão.

De qualquer sorte, inúmeros dispositivos normativos influem diretamente no comércio internacional, como no moderno mercado dos equipamentos para geração de energia renovável, e, consequentemente, emerge a necessidade de uma interpretação doutrinária e jurisprudencial para solucionar eventuais conflitos, em face da lacuna jurídica sobre determinados aspectos que incidem sobre o campo energético.

Diante desse contexto, serão apresentados, na primeira parte, aspectos relativos ao comércio de energia na OMC, como tarifas, restrições, tributação, subsídios, trânsito, meio ambiente, investimentos e disputas; e, na segunda parte, será analisada a viabilidade de um Acordo Plurilateral sobre Energia, o que se considera uma alternativa viável e acessível diante do atual conturbado cenário da Organização Multilateral.

\section{Desafios no comércio de energia na Organização Mundial do Comércio}

Nesta primeira parte, serão analisadas algumas das principais questões da OMC em relação ao setor de energia, de forma específica, no intuito de identificar o tratamento atual do setor.

\subsection{Tarifas e outras medidas aduaneiras afetando importação de bens}

\subsubsection{Tarifas de importação}

O objetivo da OMC é reduzir gradualmente as tarifas e eliminar outras barreiras de importação. Questões relativas às tarifas de importação e outras obrigações conexas estão localizadas no art. II:2, do GATT (Lista de Concessões)

Os membros negociam as tarifas máximas para cada produto, e essas tarifas máximas são indicadas num programa para cada membro. Os membros não podem aplicar tarifas superiores a este programa acordado. Poderiam aplicar tarifas inferiores, desde que respeitado o princípio da não discriminação. Todos os outros encargos e deveres impostos ou em conexão com importação são proibidos, exceto se houver reserva prevista no programa acordado.

Tarifas de importação de produtos energéticos são relativamente baixas em relação a outros produtos. O World Trade Report (2010) identificou que a média tarifária (entre 146 países) para importação de combustíveis é de $25,3 \%$, sendo que a taxa média praticada por países desenvolvidos é de $1,5 \%$ e dos países em desenvolvimento é de $27,5 \%$. Mas existe um fator externo ao comércio que determina um aumento ou redução das tarifas, que é a segurança energética, influenciando nos preços. ${ }^{2}$

Em relação aos biocombustíveis, particularmente o etanol, os EUA têm cobrado 54 centavos de dólar por galão além da tarifa de $2,5 \%$ ad valorem. A UE tarifa entre 39\% e 63\%. No caso do etanol, ele está

1 YANOVICH, Alan. WTO rules and the energy sector. In: SELIVANOVA, Yulia (Org.). Regulation of energy in international trade law: wto, nafta and energy charter. Kluwer Law International, 2011. p. 4.

2 ORGANIZAÇÃO MUNDIAL DO COMÉRCIO. World Trade Report 2010. Disponível em: <http://www.wto.org/english/res_e/ publications_e/wtr10_e.htm>. Acesso em: 10 nov. 2012. p. 115. 
classificado no capítulo 22 do sistema harmonizado, sendo tratado como um produto agrícola disciplinado no Acordo para Agricultura.

Outra questão é em relação a equipamentos utilizados para geração de energia renovável. Mais de $93 \%$ da produção de energia eólica está concentrada entre as empresas com base em sete países: Dinamarca, EUA, Espanha, Alemanha, Índia, China e Japão. ${ }^{4}$

Até 2009, a maioria dos membros da OMC impõe tarifas de importação sobre turbinas eólicas, painéis solares e turbinas a gás de grande porte (> $5 \mathrm{MW})$. Para as turbinas de vento, as tarifas são cobradas em quase 60\% (91 dos 156) dos países, com uma tarifa média de $7,4 \%$. Os painéis solares têm uma tarifa em quase $43 \%$ (65 de 156) dos países, com uma tarifa média de 8,8\%. Grandes turbinas a gás enfrentam tarifas em mais de $55 \%$ dos países (85 de 156), com uma tarifa média de $6,6 \%$

Apesar de existir uma tendência de favorecer bens ambientalmente favoráveis no âmbito da $\mathrm{OMC}^{6}$, a grande porcentagem de países que tarifam os geradores de energia pode significar: (i) uma conduta protecionista em relação à indústria doméstica; (ii) um meio de buscar receita; ou (iii) dificultar investimentos no setor, o que não é salutar para o incremento de geração de energia por meio sustentável.

3 YANOVICH, Alan. WTO rules and the energy sector. In: SELIVANOVA, Yulia (Org.). Regulation of energy in international trade law: wto, nafta and energy charter. Kluwer Law International, 2011. p. 5.

4 BURNS, Thaddeus J. The liberalization of environmental goods and services (EGS) trade and the need for a distinct EGS agreement. In: PAUWELYN, Joost. Global Challenges at the intersection of trade, energy and the environment. Genebra: The Graduate Institute, Center for Trade and Economic Integration, 2010. p. 96. Disponível em: <http://graduateinstitute.ch/ctei/publications_list/global. html> Acesso em: 15 nov. 2012.

5 BURNS, Thaddeus J. The liberalization of environmental goods and services (EGS) trade and the need for a distinct EGS agreement. In: PAUWELYN, Joost. Global Challenges at the intersection of trade, energy and the environment. Genebra: The Graduate Institute, Center for Trade and Economic Integration, 2010. p. 96-97. Disponível em: <http://graduateinstitute.ch/ctei/publications_ list/global.html>. Acesso em: 15 nov. 2012.

6 VOSSENAAR, Rene. Climate-related Single-use Environmental Goods, ICTSD. Issue Paper 13, September/2010. International Centre for Trade and Sustainable Development, Geneva, Switzerland. Disponível em: <http://ictsd.org/downloads/2011/12/climaterelated-single-use-environmental-goods.pdf $>$. Acesso em: 16 dez. 2012.

\subsubsection{Restrições de importação}

Proibição de restrições quantitativas: o art. XI do GATT dispõe que não serão permitidas proibições ou restrições instituídas ou mantidas por qualquer parte contratante sobre a importação de qualquer produto do território de outra parte contratante ou à exportação ou venda para exportação de qualquer produto destinado ao território de outra parte contratante, exceto que não sejam impostos, taxas ou outros encargos, se efetivada por meio de cotas de importação ou de exportação ou outras medidas.

Essa restrição quantitativa é prejudicial para o comércio de bens e serviços, e por isso deve ser eliminada no contexto comercial. Uma questão pode surgir na hipótese de ausência de proibição expressa da quantidade, mas a entrada do produto somente é permitida sob determinadas condições. No caso da energia, essas restrições são menos problemáticas no comércio internacional.7

\subsection{Medidas que afetam a exportação}

$\mathrm{O}$ art. XI do GATT pró́be restrições quantitativas de importação e exportação, mas permite a imposição de impostos, taxas ou outros encargos, se efetivada por meio de cotas de importação ou de exportação ou outras medidas.

Alguns países exportadores de recursos naturais têm utilizado dessa faculdade, como meio de geração de renda. Conforme o relatório World Trade Report-2014, emitido pela OMC, baseado em dados da OECD, em média, estima-se que $5 \%$ do total das exportações se referem a taxas de exportação, aumentando para $11 \%$ quando se trata especificamente de exportação de recursos naturais. ${ }^{8}$ Uma consequência do uso massivo de taxas de exportação e de outras restrições à exportação de recursos naturais é o uso do denominado Investimento Estrangeiro Direto (IED) como forma de contornar as medidas.

7 YANOVICH, Alan. WTO rules and the energy sector. In: SELIVANOVA, Yulia (Org.). Regulation of energy in international trade law: wto, nafta and energy charter. Kluwer Law International, 2011. p. 6-7.

8 ORGANIZAÇÃO MUNDIAL DO COMÉRCIO. World Trade Report 2014. Disponível em:<http://www.wto.org/english/ res_e/booksp_e/world_trade_report14_e.pdf $>$. Acesso em: 17 nov. 2014. p. 12. 
A primeira forma de contornar as restrições à exportação ocorre por meio de aquisição ou fusões com empresas estrangeiras envolvidas no setor de recursos naturais (empresas petrolíferas, empresas de mineração, etc.). Especificamente, as empresas de países importadores podem optar por investir no setor de recursos naturais no país exportador — por exemplo, mudando algumas partes do processo de produção como uma forma de evitar as restrições à exportação dos recursos naturais.?

Os investimentos diretos em recursos naturais, como a terra, em países estrangeiros podem, em parte, ter motivações semelhantes. Esse fenômeno tem atraído grande atenção recentemente. Esses investimentos frequentemente tomam a forma de arrendamentos de longo prazo, compras diretas, ou contratos agrícolas. Em muitos casos, a área adquirida é dedicada ao cultivo de plantações para alimento ou biocombustível. ${ }^{1011}$

Os investidores tendem a ser de países onde a terra arável e com água é particularmente escassa ou de economias com uma crescente demanda por alimentos, energia e matérias-primas. Os investimentos são frequentemente direcionados para países da África (como a Etiópia, Moçambique, Sudão) e no Sudeste da Ásia (Camboja, Indonésia, Filipinas), mas também em outros mais desenvolvidos e ricos em recursos, como a Ucrânia e Rússia. ${ }^{12}$

O valor das fusões transfronteiriças e aquisições no setor de recursos naturais (mineração, pedreiras e petróleo) atingiu mais de US\$ 83 bilhões dólares em 2008 , representando cerca de um oitavo do valor total de fusões e aquisições daquele ano. ${ }^{13}$ Logicamente, existem certos riscos. Nesse contexto, estão sendo

9 ORGANIZAÇÃO MUNDIAL DO COMÉRCIO. World Trade Report 2010. Disponível em: <http://www.wto.org/english/res_e/ publications_e/wtr10_e.htm>. Acesso em: 10 nov. 2012. p. 117.

10 ORGANIZAÇÃO MUNDIAL DO COMÉRCIO. World Trade Report 2010. Disponível em:<http://www.wto.org/english/res_e/ publications_e/wtr10_e.htm>. Acesso em: 10 nov. 2012.p. 117.

11 ORGANIZAÇÃO MUNDIAL DO COMÉRCIO. World Trade Report 2014. Disponível em:<http://www.wto.org/english/ res_e/booksp_e/world_trade_report14_e.pdf $>$. Acesso em: 17 nov. 2014. p. 141.

12 ORGANIZAÇÃO MUNDIAL DO COMÉRCIO. World Trade Report 2010. Disponível em:<http://www.wto.org/english/res_e/ publications_e/wtr10_e.htm>. Acesso em: 10 nov. 2012. p. 117.

13 UNCTAD. Conferência das Nações Unidas sobre Comércio e Desenvolvimento (UNCTAD), 2009. Apud ORGANIZAÇÃO MUNDIAL DO COMÉRCIO. World Trade Report 2010. Disponível em:<http://www.wto.org/english/res_e/publications_e/wtr10_e. htm>. Acesso em: 10/11/2012. p. 117. consideradas medidas para que os investimentos sejam realizados de forma sustentável, mediante políticas públicas de longo prazo, com esforços para países menos desenvolvidos. ${ }^{14}$

Ainda no aspecto da exportação, existe a questão das cotas de produção, que podem ser prejudiciais ao comércio, principalmente no tocante à exportação de petróleo, em que a OPEP tem a faculdade de limitar a produção, o que pode gerar distorções no preço do produto. Nesse caso, existem posições para ambos os lados: (i) de que a produção de cotas da OPEP está limitada ao art. XI:1 (proibição de restrições quantitativas, e (ii) outros consideram que decisões de quanto um recurso deve ser extraído recai sobre o princípio da soberania sobre os recursos naturais, e que poderia se enquadrar no art. XX (h) GATT por ser uma commodity. ${ }^{15}$ Ocorre que a OPEP não poderia ser condenada, por ser uma organização internacional não membro; cogitar-se-ia tão-somente a hipótese dos países membros da OPEP serem condenados, caso membros também da OMC.

\subsection{Tributação interna e regulação}

É tratado no art. III do GATT, e considerado como imposto sobre consumo ou venda. Diferentemente das tarifas, não houve limitação ou imposição de um teto das exigências tributárias internas que podem se aplicar aos produtos importados

Da mesma forma, o art. III do GATT permite ao Estado membro ampla discricionariedade para regular as vendas internas, ofertas, compras, transporte e distribuição de um produto importado. O que o art. III não permite é uma discriminação fiscal (art. III:2) ou regulatória (art. III:4) entre o produto importado e o semelhante doméstico, o que violaria o princípio do tratamento nacional e, se concedido um tratamento diferenciado a outro país membro em relação ao mesmo

14 UNCTAD. World Investment Report 2014. Disponível em: <http://unctad.org/en/PublicationsLibrary/wir2014_overview_ en.pdf $>$. Acesso em: 17 nov. 2014. p. 24-40.

15 WORIKA, Ibibia L. Production, Management, OPEC and the WTO. In: PAUWELYN, Joost. Global Challenges at the intersection of trade, energy and the environment. Genebra: The Graduate Institute, Center for Trade and Economic Integration, 2010. p. 87-93. Disponível em: <http://graduateinstitute.ch/ctei/publications_ list/global.html>. Acesso em: 15 nov. 2012. 
produto, poder-se-ia identificar violação ao princípio da nação mais favorecida, previsto no art. I do GATT.

Alguns países exigem tributos sobre consumo de combustíveis substancialmente superiores aos tributos sobre importação do mesmo produto. Aqueles que não são produtores de combustíveis têm uma tendência maior de impor essa exigência, sendo considerado por uma perspectiva econômica o mesmo que impor tarifas de importação. ${ }^{17}$

Nesse quesito é necessário conceituar o que seria um produto semelhante (likeness) que causaria a violação dos referidos dispositivos. Brevemente, a determinação de likeness tem sido conduzida a partir de quatro (4) critérios $^{18}$ : (i) as propriedades, natureza e qualidade do produto; (ii) as finalidades de uso do produto; (iii) gosto e hábitos do consumidor e (iv) a classificação tarifária do produto. ${ }^{19}$

\subsection{Subsídios}

O Acordo SCM (Agreement on Subsidies and Countervailing Measures) define subsídio como uma contribuição financeira por um governo que confere um benefício (Art. 1.1). Essa contribuição pode se dar na forma de transferência direta de fundos, subvenção, empréstimo ou injeções de capital; na renúncia de receita pelo governo; ou concessão de bens e serviços outros que não de infraestrutura. ${ }^{20}$

O subsídio deve ser específico a uma empresa ou indústria, ou um grupo de empresas ou indústrias, sob pena de não se enquadrar na hipótese do SCM (art.

16 YANOVICH, Alan. WTO rules and the energy sector. In: SELIVANOVA, Yulia (Org.). Regulation of energy in international trade law: wto, nafta and energy charter. Kluwer Law International, 2011. p.11-12.

17 YANOVICH, Alan. WTO rules and the energy sector. In: SELIVANOVA, Yulia (Org.). Regulation of energy in international trade law: wto, nafta and energy charter. Kluwer Law International, 2011. p. 11-12.

18 Ver decisão do Órgão de Apelação da OMC do caso JapanTaxes on Alcoholic Beverages. Disponível em: <http://www.wto.org/ english/tratop_e/dispu_e/cases_e/ds8_e.htm>. Acesso em: 28 jan. 2014.

19 YANOVICH, Alan. WTO rules and the energy sector. In: SELIVANOVA, Yulia (Org.). Regulation of energy in international trade law: wto, nafta and energy charter. Kluwer Law International, 2011. p. 11-12.

20 ORGANIZAÇÃO MUNDIAL DO COMÉRCIO. Acordo SCM. Disponível em: <http://www.wto.org/english/docs_e/ legal_e/24-scm.pdf>. Acesso em: 10 out. 2012.
2). Diferentes disposições são aplicadas a diferentes espécies de subsídios conforme o grau de distorção do mercado internacional. Subsídios para exportação e subsídios condicionados ao uso de bens domésticos são proibidos. Outros subsídios são acionáveis, o que significa que outros membros da OMC podem tomar medidas contra eles somente na hipótese de causar efeitos adversos. ${ }^{21}$

Duas medidas podem ser tomadas contra os subsídios proibidos ou acionáveis: (i) um membro pode aplicar deveres adicionais de importação (countervailing duties) aos bens importados subsidiados, desde que demonstrado o prejuízo. (ii) Outra opção é recorrer ao OSC, quando os subsídios causarem ou ameacem causar prejuízos à indústria doméstica do reclamante, mas também onde o uso dos subsídios causem outros efeitos adversos, como deslocando ou impedindo as exportações para um mercado de terceiro país, efeitos nos preços (preço abaixo do mercado, supressão ou depressão, ou vendas perdidas), ou aumentando a fatia do mercado do membro subsidiante. ${ }^{22}$

Em relação ao tema da energia, estima-se que os subsídios podem estar promovendo um consumo superior ao necessário de combustíveis fósseis, contribuindo para a mudança climática. A Agência Internacional de Energia calculou que os subsídios nesse setor poderiam exceder US $\$ 550$ bilhões por ano. Se eles fossem zerados, o mundo deixaria de consumir até 2020850 milhões de toneladas de petróleo, o que representa o consumo de Japão, Coreia do Sul, Austrália e Nova Zelândia juntos. ${ }^{23}$

Outra preocupação é que os subsídios podem ser necessários para o desenvolvimento e implantação de energia renovável. No caso, o art. $8^{\circ}$, que determinava a exceção para subsídio não acionáveis, ou seja, para atividades de pesquisas, assistência para regiões carentes e assistência para promover adaptação às

21 YANOVICH, Alan. WTO rules and the energy sector. In: SELIVANOVA, Yulia (Org.). Regulation of energy in international trade law: wto, nafta and energy charter. Kluwer Law International, 2011. p. 17.

22 YANOVICH, Alan. WTO rules and the energy sector. In: SELIVANOVA, Yulia (Org.). Regulation of energy in international trade law: wto, nafta and energy charter. Kluwer Law International, 2011. p. 17.

23 YANOVICH, Alan. WTO rules and the energy sector. In: SELIVANOVA, Yulia (Org.). Regulation of energy in international trade law: wto, nafta and energy charter. Kluwer Law International, 2011. p. 17. 
novas necessidades ambientais, não foi renovado e não vigora mais. Uma saída seria a aplicação do art. XX do GATT, mas que poderia ser questionada por se tratar de matéria de outro acordo (SCM), e não do GATT, como dispõe seu caput. ${ }^{24}$

Os recentes casos apresentados ao OSC da OMC (vide Anexo II) têm como fundamento, entre outros, a violação do acordo SCM, pelo fato de promover a exportação e condicionar as aquisições de equipamento mediante o requisito de conteúdo doméstico. No entanto, mesmo os casos sendo relacionados com energia renovável, não houve até a presente data qualquer alegação de aplicação da exceção do art. XX, do GATT, pelos reclamados.

Conforme Thorstensen os subsídios para o setor de energia são conferidos a produtores e indústrias mediante:

[...] pagamentos diretos para financiar a produção; subsídios relacionados à tributação; políticas para redução do custo de insumos; subsídios relacionados a investimentos (como empréstimos a juros preferenciais, remissão de dívidas, empréstimos de garantias, entre outros); e políticas que geram transferência de preços por meio do mercado. ${ }^{25}$

Os conceitos do Acordo SCM foram criados focando para o comércio de bens, e não podem ser aplicados diretamente aos investimentos, pois se referem aos fluxos de bens, que ocorrem depois que o investimento tiver sido feito. Os efeitos adversos estabelecidos no Acordo estão definidos como distorções do fluxo comercial dos bens subsidiados, ou seja, na medida em que os subsídios aumentam o nível de exportação ou reduzem nível de importação do país que subsidia e, assim, prejudicam os produtores de produtos similares em outro país. ${ }^{26}$

Isso demonstra a distinção entre subsídio e investimento. $\mathrm{O}$ subsídio, mesmo podendo ser

24 PEAT, Daniel. The Wrong Rules for the Right Energy: the wto scm agreement and subsidies for renewable energy. Environmental law and management. n. 3, 2012. p. 14-15. Disponível em: <http:// ssrn.com/abstract $=1998240$ or http://dx.doi.org/10.2139/ ssrn.1998240>. Acesso em: 16 maio 2012.

25 THORSTENSEN, Vera; et. al. A regulação do comércio internacional de energia: combustíveis e energia elétrica. São Paulo: FIESP, 2013. p.99.

26 THORSTENSEN, Vera. A OMC - Organização Mundial do Comércio e as negociações sobre investimentos e concorrência. Revista Brasileira de Política Internacional, Brasília, v. 1, n. 41, p. 57-89, 1998. p. 69-70. Disponível em: <http://www.scielo.br/pdf/rbpi/ v41n1/v41n1a04>. Acesso em: 06 fev. 2014. uma contribuição financeira, não é considerado um investimento em si, pelo simples fato de ser o meio pelo qual o investimento será realizado.

\subsection{Trânsito}

A OMC considera a ocorrência de trânsito quando há uma passagem de um produto por um território de um membro, sendo esse local de passagem não o seu destino final. Inclusive, se considera que a passagem em territórios outros que não o seu destino final é como se o produto tivesse sido transportado diretamente, como se jamais tivesse passado por outro território

O tema do trânsito de energia é complexo, uma vez que a OMC coloca como se fosse trânsito de bens (considerando que trânsito de energia é algo bem mais complexo, podendo ser por oleodutos, gasodutos, sem citar a questão da energia elétrica por redes).

No que diz a esse respeito, o artigo V do GATT de 1994 fornece um conjunto relativamente limitado de regulamentos e alguns estudiosos chegam a argumentar que ainda é discutível se o artigo V do GATT é aplicável ao trânsito de energia.

No entanto, questiona-se se o trânsito previsto no art. V se aplica a transportes móveis, como embarcações, ou se aplica ao trânsito por estruturas fixas, como tubulações. A expressa exclusão de aeronaves no art. V:7 e a ampla definição de "tráfego no trânsito" no art. $\mathrm{V}: 1$, apoia a posição que o trânsito via tubulações ou outras estruturas de redes fixas é matéria aplicável pelo art. V, do GATT. $^{27}$

Considerando-se que o art. V se aplica somente a Estados membros, outras questões podem surgir: se as estruturas são de propriedade de entes privados, qual extensão pode ser aplicado o art. V, do GATT? E, como ficam as estruturas de propriedade de empresas estatais? ${ }^{28}$

A Ucrânia, que é um país chave na passagem de gás e petróleo da Eurásia para a Europa, e cobra por isso, se

27 THORSTENSEN, Vera. A OMC - Organização Mundial do Comércio e as negociações sobre investimentos e concorrência. Revista Brasileira de Política Internacional, Brasília, v. 1, n. 41, p. 57-89, 1998. Disponível em: <http://www.scielo.br/pdf/rbpi/v41n1/ v41n1a04>. Acesso em: 06 fev. 2014.

28 SELIVANOVA, Yulia. The WTO and Energy WTO Rules and Agreements of Relevance to the Energy Sector. International Centre for Trade and Sustainable Development - ICTSD. Disponível em: <http://ictsd. org/downloads/2008/05/the20wto20and20energy.pdf $>$. Acesso em: 24 out. 2011. 
comprometeu no momento das negociações à acessão a respeitar o art. V do GATT, submetendo suas normas e demais regulamentos. Esse tema é tão relevante para aquele país que o compromisso firmado se refere especificamente à energia, e cobre não somente leis e regulamentos relativos ao trânsito, mas também outras medidas. $^{29}$

Por exemplo, na questão do trânsito, alguns membros manifestaram a sua preocupação no que diz respeito às taxas cobradas para o trânsito de produtos energéticos por meio de gasodutos quando definido em um ambiente não competitivo, não transparente, contrário ao Artigo V, do GATT. Outros argumentaram que as diferentes taxas de transporte em diferentes rotas de trânsito de petróleo conflitam com as disposições de liberdade de trânsito do artigo V, do GATT.

Considerando-se as práticas vigentes na indústria de energia, em que tubulações são, em sua maioria, construídas e geridas por empresas estatais ou empresas com monopólio, e considerando-se a inaplicabilidade do artigo $\mathrm{V}$ do GATT em entidades privadas, verificase certa inadequação da OMC em lidar com o trânsito no comércio de energia. ${ }^{30}$

\subsection{Serviços}

O GATS é aplicável a todos os serviços, exceto serviços fornecidos no exercício de autoridade governamental (art. I:3(b)) e direitos e serviços de tráfico aéreo diretamente ligado ao exercício desses direitos (Anexo do GATS relativo a transporte aéreo)

Foram definidos quatro modos de fornecimento de serviços (art. I:2, GATS):

Do território de um Estado-Membro para o território de qualquer outro membro; (cross-border trade);

No território de um membro para o consumidor de serviços de qualquer outro membro; (consumption abroad);

29 MARCEAU, Gabrielle. The WTO in the Emerging Energy Governance Debate. In: PAUWELYN, Joost. Global Challenges at the intersection of trade, energy and the environment. Genebra: The Graduate Institute, Center for Trade and Economic Integration, 2010. p. 32. Disponível em: <http://graduateinstitute.ch/ctei/publications_ list/global.html>. Acesso em: 15 nov. 2012.

30 SHIH, Wen-chen. Energy Security, GATT/WTO and Regional Agreements. SIEL, n. 10. 2008. p. 41.
Por um prestador de serviços de um membro por meio da presença comercial no território de qualquer outro membro (commercial presence);

Por um prestador de serviços de um Membro, por meio da presença de pessoas físicas de um membro no território de qualquer outro membro (presence of natural persons).

O GATS estabelece, entre outras, obrigações de acesso ao mercado, não discriminação (tratamento nacional e NMF) e transparência. As obrigações de acesso ao mercado (art. XVI) e o tratamento nacional (art. XVII) se aplicam somente em setores e modos de fornecimento que cada Estado membro havia especificado no seu programa de compromissos específicos. $\mathrm{Na}$ ausência desses compromissos, o GATS impõe obrigações gerais mais limitadas, como a NMF.

A classificação setorial de serviços (MTN/ GNS/w/120) que foi usada como base para programar os compromissos sob o GATS não incluiu a energia como um setor. Somente incluiu três subsetores em relação ao setor de energia:

- Serviços de mineração;

- Serviços de distribuição de energia;

- Transporte de combustíveis.

Deve-se relembrar o que foi referido no início desse estudo, que é a dificuldade em se identificar onde classificar determinado serviço, por exemplo. Pode-se até questionar se o trânsito de energia não seria um serviço.

Como exemplo, já houve a discussão no tema da extração de petróleo: para a OMC, a perfuração é um serviço incidente sobre mineração se estiver baseado numa relação contratual e realizado por uma entidade distinta; mas pode constituir um valor adicionado se o produto é extraído pelo próprio proprietário do petróleo. E isso pode se aplicar a liquefação de gás, refino de petróleo e regasificação. ${ }^{31}$

31 YANOVICH, Alan. WTO rules and the energy sector. In: SELIVANOVA, Yulia (Org.). Regulation of energy in international trade law: wto, nafta and energy charter. Kluwer Law International, 2011. p. 32. 


\subsection{Conservação ambiental}

A OMC reconhece que a expansão da produção e do comércio deve permitir e promover a otimização do uso dos recursos naturais mundiais conforme o princípio do desenvolvimento sustentável

Em abril de 1987, a Comissão Brundtland, como ficou conhecida, publicou um relatório inovador denominado "Nosso Futuro Comum", que traz o conceito de desenvolvimento sustentável para o discurso público: “o desenvolvimento sustentável é o desenvolvimento que encontra as necessidades atuais sem comprometer a habilidade das futuras gerações de atender suas próprias necessidades." 32

Em primeiro lugar, é entendimento generalizado que a OMC não se aplica a recursos naturais no seu estado natural, como petróleo e carvão, ou seja, antes da extração (critério). No entanto, uma previsão governamental concedendo incentivos à madeira plantada (em pé) para uma empresa privada que remunerará o governo por menos que o considerado adequado no mercado, pode constituir subsídios no sentido do Agreement on Subsidies and Countervailing Measures (SCM Agreement). ${ }^{33}$

Ressalta-se a opinião da própria OMC, no World Trade Report 2010:

Visões têm sido alteradas ao longo do tempo questionando se os recursos naturais são uma bênção ou uma maldição para o desenvolvimento econômico. Muitos economistas entendem que o legado dos recursos naturais é essencial como uma vantagem comparativa dos países, mas crítico para o crescimento econômico, enquanto outros alegam que a dependência da exportação dos recursos naturais podem prender países em estado de subdesenvolvimento. ${ }^{34}$ (tradução nossa)

32 ORGANIZAÇÃO DAS NAÇÕES UNIDAS. Comissão Brundtland "Nosso Futuro Comum". Disponível em: <http:// www.onu.org.br/a-onu-em-acao/a-onu-e-o-meio-ambiente/>. Acesso em: 05 out. 2012.

33 YANOVICH, Alan. WTO rules and the energy sector. In: SELIVANOVA, Yulia (Org.). Regulation of energy in international trade law: wto, nafta and energy charter. Kluwer Law International, 2011. p. 3.

34 ORGANIZAÇÃO MUNDIAL DO COMÉRCIO. World Trade Report 2010. Disponível em: <http://www.wto.org/english/ res_e/publications_e/wtr10_e.htm>. Acesso em: 10 nov. 2012.
Ainda, as regras da OMC não são competentes para regular propriedade dos recursos naturais, incluindo recursos energéticos, seja entre Estados, seja entre Estados e privados. Isso porque ela vincula os governos estatais, e somente indiretamente os privados.

$\mathrm{O}$ art. XX dispõe sobre as exceções gerais. Nada neste acordo deve ser interpretado para impedir a adoção ou a aplicação por qualquer parte contratante de medidas:

(b) necessárias para proteger humana, animal ou vegetal saúde;

(g) para a conservação de recursos naturais esgotáveis, se tais medidas forem aplicadas juntamente com restrições à produção ou ao consumo nacionais.

Mas as medidas devem cumprir os critérios do Chapeau do art. XX, exigindo que não sejam aplicadas de forma a constituírem um meio de discriminação arbitrária ou injustificável entre países onde prevalecem as mesmas condições, ou uma restrição disfarçada ao comércio internacional.

O GATS confere exceção no art. XIV, mas não inclui conservação de recursos naturais exauriveis, o que seria uma total incoerência. ${ }^{35}$ Isso levantou a questão se poderia ser aplicado o art. XX, do GATT, ao SCM Agrement.

O primeiro caso apreciado pelo OSC da OMC, e coincidentemente ligado ao tema da energia, foi o caso US - Reformulated Gasoline, que foi paradigmático ao permitir a análise do art. XX do GATT. Nesse caso, os Estados Unidos da América (EUA) aprovaram o Clean Air Act e suas regras de implementação, como a Gasoline Rule, no intuito de reduzir a poluição do ar.

Para tanto, em áreas de alto grau de poluição do ar, somente uma gasolina especial, reformulada, poderia ser vendida, e em demais áreas foi permitida a venda de gasolina não mais "suja" que as vendidas nos anos 1990. A Gasoline Rule foi destinada às refinarias, petroquímicas e importadores, e determinava requisitos com certas características químicas, numa média anual, com níveis definidos. Alguns níveis eram expressamente definidos pelo regulamento, mas outros indicavam critérios de não degradação para que fosse comercializada.

35 MARCEAU, Gabrielle; WYATT, J. Trade and the environment: the WTO's efforts to balance economic and sustainable development. p. 231. Apud YANOVICH, Alan. WTO rules and the energy sector. In: SELIVANOVA, Yulia (Org.). Regulation of energy in international trade law: wto, nafta and energy charter. Kluwer Law International, 2011. p. 36. 
Para demonstrar a base individual dos níveis de "pureza" da gasolina, conforme os critérios estabelecidos, as empresas deviam comprovar a qualidade do produto no ano de 1990 (método 1), e, se não fosse possível, após essa data (método 2 e 3). Os importadores também deveriam provar, mas somente poderiam utilizar como prova a gasolina no ano de 1990, e não posteriormente (método 1). Se não fosse possível, os critérios seriam conforme uma presunção legal estabelecida pelos EUA.

Por se sentirem prejudicados, Venezuela e Brasil reclamaram na OMC, invocando violação ao princípio do tratamento nacional, uma vez que a gasolina produzida era inferior aos standards da Gasoline Rule.

Objetivamente, o Órgão de Apelação julgou inconsistente a Gasoline Rule, pelo fato que a alegação pelos EUA de que os critérios seriam para evitar um dano ambiental, fundamentado na exceção do art. $\mathrm{XX}$, g, do GATT, não satisfez o teste do Chapeau do art. XX, que dispõe que a medida não deve ser uma discriminação injustificada ou uma restrição disfarçada, não cumprindo o teste de necessidade, além de que poderia ter sido utilizada outra medida menos restritiva e menos inconsistente com o GAT'T para a proteção ambiental. ${ }^{36}$

O Órgão de Apelação entendeu que os EUA não levaram em consideração os interesses e os custos das refinarias estrangeiras quando houve a implementação dos métodos restritivos, além de que poderiam ter promovido uma cooperação entre os governos interessados, estendendo os mesmos métodos utilizados no âmbito interno. Houve uma restrição à importação de certa qualidade de gasolina, incorrendo em medida restritiva de comércio, e violou um dos núcleos fundamentais do GATT, que é o princípio do tratamento nacional.

Além disso, a obrigação de um membro em considerar os custos de uma medida sobre outros membros pode ser compreendido como uma aplicação objetiva do desenvolvimento sustentável, considerando os princípios do uso sustentável, igualitário e integrado. Em relação ao primeiro, deve ser levado em consideração que o estágio de desenvolvimento de um país define

36 NAPPERT, Sophie; ORTINO, Federico. International resolution of energy trade and investment dispute. In: SELIVANOVA, Yulia (Org.). Regulation of energy in international trade law: wto, nafta and energy charter. Kluwer Law International: 2011. p. 313 . sua capacidade técnica para adotar medidas. No caso concreto, Brasil e Venezuela não tinham as mesmas capacidades técnicas que os EUA, o que impediria a adoção das regras impostas. ${ }^{37}$

O princípio do uso igualitário implica que o uso de determinado recursos por um país (no caso os EUA) deve levar em conta a necessidade de outros países (Brasil e Venezuela), o que não ocorreu. E, por fim, as medidas ambientais impostas pelos EUA nunca consideraram a integração com outras questões afins, como o nível de desenvolvimento econômico dos países afetados, afrontando o princípio da integração. ${ }^{38}$

Apesar do Clean Air Act possuir um objetivo de reduzir as emissões de poluentes atmosféricos, esse discurso não convenceu o Órgão de Apelação, principalmente pelo fato de que outras medidas poderiam ser adotadas com o mesmo efeito, sem, contudo, prejudicar os outros membros da OMC. Esse argumento é substantivo para análise de futuros casos a serem apreciados.

\subsection{Investimento}

A OMC não inclui acordos específicos sobre investimento. O TRIMS não trata de proteção do investimento, mas proíbe os membros de imporem níveis particulares de aquisições locais por uma empresa (local content requirements) ou requisitando que uma empresa restrinja o volume ou valor das importações ao montante relacionado ao nível de produtos exportados (trade balancing requirements). Esse acordo aplica-se a medidas de investimento relacionadas somente ao comércio de bens.

\subsection{Disputas}

Um fator que merece uma atenção especial é que os conflitos no comércio de energia são caracterizados

37 MOROSINI, Fábio Costa; MARCEAU Gabrielle. The status of sustainable development in the law of the World Trade Organization. p. 59-92. In: CELLI JUNIOR, Umberto; BASSO, Maristela; AMARAL JUNIOR, Alberto do. (Coord.). Arbitragem e comércio internacional: estudos em homenagem a Luiz Olavo Baptista. São Paulo: Quartier Latin, 2013. p. 81.

38 MOROSINI, Fábio Costa; MARCEAU Gabrielle. The status of sustainable development in the law of the World Trade Organization. p. 59-92. In: CELLI JUNIOR, Umberto; BASSO, Maristela; AMARAL JUNIOR, Alberto do. (Coord.). Arbitragem e comércio internacional: estudos em homenagem a Luiz Olavo Baptista. São Paulo: Quartier Latin, 2013. p. 81. 
pela presença de obstáculos para a fluidez dos produtos energéticos pelas fronteiras dos países. Como já referido no início do trabalho, um sistema de solução de controvérsias foi criado no âmbito da OMC para solucionar eventuais disputas comerciais.

A OMC constituiu um Entendimento de Solução de Controvérsias (ESC - Dispute Settlement Understanding - DSU), que é o grande diferencial em relação ao GATT/1947, cabendo a aplicação das normas ao Órgão de Solução de Controvérsias (OSC).

Conforme Celso Lafer, como principal característica, verifica-se o "adensamento de juridicidade" das decisões do Órgão, que vinculam as partes ao seu cumprimento. Ou seja, o ESC visa mais do que o cumprimento de uma mera "obrigação de comportamento", a ser seguida de boa-fé, como no caso de transparência (art. 2(3) da Carta da ONU). Objetiva uma "obrigação de resultado", como medida de construção da confiança (confidence building measure), tutelando segurança e previsibilidade do sistema multilateral de comércio ${ }^{39}$

As disputas iniciam quando um membro requer uma consulta por que considera que benefícios estão sendo prejudicados direta ou indiretamente em face da violação dos acordos por outro membro. Se as consultas não resultarem em um acordo amigável, um Painel é estabelecido, composto por três julgadores. Da decisão do painel cabe apelação ao Órgão de Apelação.

O OSC administra o procedimento, e tem a função de autorizar as contramedidas adjudicantes, se for o caso. E nesses casos podem ocorrer disputas em razão de medidas governamentais que restringem (i) a exportação de produtos de energia (taxas e obrigações alfandegárias de exportação, podendo incluir cotas de produção); (ii) importação de produtos de energia (tributação e regulação interna, incluindo medidas sobre câmbio climático), e (iii) trânsito em energia (condução por monopólios estatais e empresas de comércio estatais que operam a infraestrutura de energia). Ainda, os conflitos no setor do comércio podem ocorrer em face da prestação de serviços de energia. ${ }^{40}$

39 LAFER, Celso. A OMC e a regulamentação do comércio internacional: uma visão brasileira. Porto Alegre: Livraria do Advogado, 1998. p. 31-32.

40 NAPPERT, Sophie; ORTINO, Federico. International resolution of energy trade and investment dispute. In: SELIVANOVA, Yulia (Org.). Regulation of energy in international trade law: wto, nafta and energy charter. Kluwer Law International: 2011. p. 304.
Dentro desse contexto, segue-se para uma análise do mecanismo para solução de controvérsias em relação ao setor energético no âmbito da OMC, com breves comentários comparativos com o do ECT.

Conforme art. 23.1 do DSU, a jurisdição é compulsória e exclusiva por natureza, com exclusão de qualquer outro sistema. ${ }^{41}$ Apenas para complementar a questão jurisdicional, o Energy Charter Treaty (ECT) refere que no caso de comércio, se os Estados judicantes também forem ambos membros da OMC, o caso será levado ao OSC..$^{42}$ Em relação a disputas decorrentes do trânsito de energia, o ECT dispõe de um mecanismo especializado de conciliação, permitindo maior rapidez com menor formalidade no procedimento (art. 7(7) ECT), e o OSC nada dispõe sobre esta matéria específica. ${ }^{43}$

Surge o questionamento das causas e/ou razões de reduzidos conflitos no setor energético na OMC. Mesmo compreendendo uma relevante parcela do comércio internacional, o tema não foi objeto de reclamações ao OSC. Numa análise quantitativa de disputas em comércio de energia, poucos casos foram identificados em comparação com o número total de conflitos apreciados pelo OSC.

Em primeiro lugar, isso se deve ao fato que muitos exportadores de energia não são membros da $\mathrm{OMC}$, como Argélia, Azerbaijão, Irã, Iraque, Cazaquistão, Líbia e Turcomenistão, e outros recém se tornaram membros, como Rússia (2012) e Arábia Saudita (2005). Outra questão é que no setor de energia, em regra, as restrições ou barreiras ao fluxo de produtos são estabelecidas por países exportadores, e não importadores, e essas restrições caem sob a disposição do art. XI do GATT, não tão visado pelo sistema multilateral. ${ }^{44}$

41 BOSSCHE, Peter Van Den. The law and policy of the world trade organization: text, cases and materials. 2 ed. Cambridge: Cambridge University Press, 2010. p. 180.

42 SELIVANOVA, Yulia. The Energy Charter Treaty and the international energy governance. In: SELIVANOVA, Yulia (Org.). Regulation of energy in international trade law: WTO, nafta and energy charter. Kluwer Law International, 2011. p. 378.

43 NAPPERT, Sophie; ORTINO, Federico. International resolution of energy trade and investment dispute. In: SELIVANOVA, Yulia (Org.). Regulation of energy in international trade law: WTO, nafta and energy charter. Kluwer Law International: 2011. p. 308.

44 NAPPERT, Sophie; ORTINO, Federico. International resolution of energy trade and investment dispute. In: SELIVANOVA, Yulia (Org.). Regulation of energy in international trade law: WTO, nafta and energy charter. Kluwer Law International: 2011. p. $314-315$. 
Numa comparação entre os reduzidos casos de energia na OMC com os casos relacionados a investimentos em energia baseados em tratados internacionais de investimento, alguns fatores devem ser enfatizados.

Primeiro, os tratados internacionais de investimento, representados pelos Bilateral Investment Treaties (BITs) e pelo próprio Energy Charter Treaty (ECT), dispõem sobre garantias de proteção ao investimento que não são cobertos pela OMC. Esses tratados contêm previsões impondo ao Estado hospedeiro uma obrigação (i) de compensar o investidor estrangeiro no caso de expropriação, (ii) de tratar o investidor estrangeiro de maneira justa e equitativa e (iii) de garantir ao investidor estrangeiro proteção integral e segurança; (iv) além de respeitar qualquer obrigação assumida em relação ao investimento estrangeiro. ${ }^{45}$

Os investimentos em energia são peculiares, pois envolvem, na maioria dos casos, volumosas transferências de capital, em tese sempre com uma concessão governamental do Estado hospedeiro; e uma natureza politicamente sensível de várias operações de energia, quando se relaciona com recursos naturais e que pode gerar renda para vários Estados. E esses tratados são base crucial para promover e garantir o investimento estrangeiro no setor energético. Apesar de existir no sistema da OMC dispositivos sobre investimento, como o TRIMS e GATS, eles não preveem qualquer garantia e proteção ao investidor, pois sua função é promover a liberalização do comércio de bens e serviços, eliminando medidas protecionistas e restrições quantitativas em serviços. ${ }^{46}$

Em segundo lugar, o fato que somente Estados são legítimos a reclamarem ao OSC da OMC é um fator que pode justificar o baixo índice de casos nesta matéria. Ao se comparar casos Estado versus Estado e Investidor versus Estado no âmbito dos tratados multilaterais como regionais e bilaterais, incluindo ECT e NAFTA, verifica-se que (i) é complicado o investidor convencer o Estado a assumir sua causa perante o sistema 45 NAPPERT, Sophie; ORTINO, Federico. International resolution of energy trade and investment dispute. In: SELIVANOVA, Yulia (Org.). Regulation of energy in international trade law: WTO, nafta and energy charter. Kluwer Law International: 2011. p. 316.

46 NAPPERT, Sophie; ORTINO, Federico. International resolution of energy trade and investment dispute. In: SELIVANOVA, Yulia (Org.). Regulation of energy in international trade law: WTO, nafta and energy charter. Kluwer Law International: 2011. p. 316. multilateral e (ii) apesar de haver uma preocupação do investidor em demandar um Estado, por "fechar a porta" para futuros negócios (principalmente quando se trata de recursos naturais), há forte interesse do investidor ser restituído. ${ }^{47}$

Terceiro lugar, o investidor tem pleno controle do procedimento arbitral, e dos recursos disponíveis, com uma participação direta e podendo receber a compensação na forma de danos, em contraposição a sanções previstas na OMC. Quarto lugar, em regra os contratos estabelecidos entre o investidor e o Estado hospedeiro preveem cláusula de estabilização, recurso ao tribunal estabelecido pela Convenção da ICSID (se cabível), e demais disposições que são reflexos ou se assemelham aos tratados internacionais celebrados. ${ }^{48}$

Esses fatores podem explicar o porquê que poucos casos envolvendo o tema energético foram trazidos à apreciação da OMC.

Após a decisão do caso US - Reformulated Gasoline, desde 2010, a OMC tem recebido consultas e painéis no tema de energia renovável, o que propõe que o comércio desse setor tem sido disputado com forte concorrência internacional, devido a alguns fatores, como o forte investimento em equipamentos para geração de energia elétrica por fontes limpas, principalmente eólica e solar. E também pela constante preocupação na redução de emissão de poluentes, além do gradual aumento da demanda global por energia.

Isso demonstra que existe uma evolução tecnológica, criou-se um mercado em expansão, em decorrência do investimento nesse tipo de tecnologia. Logicamente, os agentes econômicos investiram quantias consideráveis para produzir seus equipamentos, e agora desejam também protegê-los.

Os Estados protegem sua indústria mediante regulamentos domésticos, sem se preocupar com os acordos firmados no âmbito multilateral. $O$ ponto é se as medidas protetivas violam ou não os acordos da OMC. Com exceção do caso biodiesel, os demais se

47 NAPPERT, Sophie; ORTINO, Federico. International resolution of energy trade and investment dispute. In: SELIVANOVA, Yulia (Org.). Regulation of energy in international trade law: WTO, nafta and energy charter. Kluwer Law International: 2011. p. 316.

48 NAPPERT, Sophie; ORTINO, Federico. International resolution of energy trade and investment dispute. In: SELIVANOVA, Yulia (Org.). Regulation of energy in international trade law: WTO, nafta and energy charter. Kluwer Law International: 2011. p. 317. 
referem a equipamentos para geração de energia, mas todos são considerados como produtos, sujeitos aos mesmos tratamentos.

Abaixo seguem os casos identificados em relação a essa matéria. Salienta-se que os casos são recentes, e estão pendentes de decisão, com exceção dos casos canadenses (julgados de forma conjunta), em que houve a condenação do reclamado por proteger a indústria de equipamentos para geração de energia fotovoltaica da província de Ontario, mediante regras de conteúdo local. No Anexo II, estão sinteticamente demonstrados todos os dispositivos supostamente violados alegados pelos Estados requerentes. ${ }^{49}$

São eles: (i) DS 412 - Canadá - Certain measures affecting the renewable energy generation sector e DS 426 Canadá - Measures relating to the feed-in tariff program (ii) DS 419 - China - Measures concerning wind power equipment; (iii) DS 443 - UE e Espanha - Biodiesel; (iv) DS452 - UE, Grécia e Itália - Certain measures affecting the renewable energy generation sector e (v) DS 456 - Índia Certain measures relating to solar cells and solar modules.

Os casos trazidos para esse estudo demonstram que até o presente momento não houve decisão apreciando o art. XX, do GATT 1994, no setor de energia renovável. Tanto é que no caso DS 412/DS 419, os reclamantes não contestaram os objetivos do Canadá com o programa FIT, que é reduzir a emissão de carbono e promover a geração de energia elétrica por fontes renováveis.

O Japão afirmou que não se trata de disputas entre comércio e meio-ambiente, mas sim de comércio e investimento, pelo fato de promover as indústrias de produção de equipamento locais em detrimento de outras estrangeiras. Conforme o Painel, o Canadá não contestou a alegação que as medidas são relacionadas com comércio e investimento, afetando a importação de equipamentos de geração de energia por fonte renovável. Os casos estão diretamente relacionados aos equipamentos para geração de energia elétrica, como turbinas eólicas, placas solares, que são utilizados para gerar eletricidade, e não energia em si mesmo, como os combustíveis ou energia elétrica.

Dessa forma, o caso US - Reformulated Gasoline ainda poderá ser utilizado como parâmetro para eventual

49 Todas as informações das disputas foram obtidas no site da ORGANIZAÇÃO MUNDIAL DO COMÉRCIO. Disponível em: $<$ http://www.wto.org/english/tratop_e/dispu_e/dispu_status_e. htm>. Acesso em: 15 fev. 2013. apreciação de casos que envolvam a exceção prevista no art. XX, g, do GATT 1994.

A OMC, portanto, é uma organização extremamente relevante no sentido de regulamentar o comércio internacional de bens e serviços, estabelecendo parâmetros, que sempre foi seu principal objetivo. No entanto, ela acaba sendo o palco de intenso conflito de interesses dos seus membros, dificultando sua atualização. Como consequência, sua abordagem em determinados assuntos, como energia, acaba não evoluindo como deveria.

\section{Viabilidade de um acordo plurilateral sobre energia}

Em se tratando de comércio internacional de energia, inequívoca a necessidade de avaliar a possibilidade de um acordo específico sobre energia na Organização Mundial do Comércio.

Em razão de que poucos países possuem recursos naturais capazes de gerar energia e em face de, em regra, quase todos os países dependerem dela, o comércio de combustíveis (especialmente o petróleo) foi fundamental para satisfazer as necessidades globais. Há mais comércio internacional em petróleo do que qualquer outro produto. Isso se explica pela quantidade ou volume, pelo seu valor, ou a capacidade de transporte necessária para mover uma mercadoria. Uma estimativa conservadora coloca o comércio de energia em aproximadamente $20 \%$ do comércio total de mercadorias, e a metade do comércio mundial em serviços é intensamente dependente de energia. ${ }^{50}$

O jurista Arghyrios Fatouros expõe um fator complicador: que os recursos naturais, que são as principais fontes de energia, como petróleo, carvão ou gás natural, em regra, são extraídos em locais distintos de onde serão utilizados. Como exemplo, ele afirma que a Europa produz menos de $10 \%$ do petróleo no mundo, mas consome mais de $22 \%$. Os Estados Unidos da América (EUA) produzem menos de 20\% de petróleo mundial e consome mais de 30\%. Se forem contabilizadas as reservas de petróleo, essa diferença aumenta ainda mais. A Europa possui $2 \%$, os EUA $8 \%$, enquanto o Oriente Médio possui mais de $65 \% .^{51}$

50 PAUWELYN, Joost. Global Challenges at the intersection of trade, energy and the environment. Genebra: the graduate institute, center for trade and economic integration, 2010. p. 3-4. Disponível em: $<$ http://graduateinstitute.ch/ctei/publications_list/global.html> Acesso em: 15 nov. 2012.

51 FATOUROS, Arghyrios A. an international legal framework 
Isso demonstra que os atores que consomem energia têm que adquirir os recursos daqueles que produzem em localidade distinta, gerando forte fluxo de produtos e divisas, caracterizando-se como um forte comércio internacional. No entanto, estranhamente, a OMC não tem historicamente se preocupado com o comércio de energia.

Gabrielle Marceau afirma que as regras da OMC não foram inicialmente projetadas para resolver problemas de energia em si mesmo. Ao mesmo tempo, essa falta de interesse pode ser explicada de forma relativamente fácil. ${ }^{52}$

O sistema de comércio é focado em convencer os países a reduzir as restrições de importação. Quando se trata de energia, no entanto, restrições de importação não é o problema (poucos países impõem deveres de importação sobre petróleo). Em vez disso, o que importa é gestão da produção e estabilidade de preços para exportadores de energia, e acesso a produtos estrangeiros (ou de produção, exportação e restrições de trânsito) para os importadores de energia. ${ }^{5 .}$

De fato, o setor de energia parece incluir tanto aspectos de comércio de bens e de serviços. A jurisprudência da OMC é clara que uma única atividade comercial e até mesmo uma única medida podem estar cobertas pelas regras tanto do GATT quanto do Acordo Geral sobre o Comércio de Serviços.

Fica a questão de que, apesar das disciplinas do GATT serem geralmente aplicáveis a todos os produtos (enquanto todas as disciplinas do GATS não são aplicáveis a todos os serviços), é preciso esclarecer quais os aspectos do comércio de energia são abrangidas pelas regras desses e de outros acordos da OMC. ${ }^{54}$

for energy, collected courses of The Hague Academy of International Law. Martinus Nijhoff Publishers, The Hague, v. 332, p. 355-446, 2008.

52 MARCEAU, Gabrielle. The WTO in the Emerging Energy Governance Debate. In: PAUWELYN, Joost. Global Challenges at the intersection of trade, energy and the environment. Genebra: the graduate Institute, Center for Trade and Economic Integration, 2010. p. 25. Disponível em: <http://graduateinstitute.ch/ctei/publications_ list/global.html> Acesso em: 15 nov. 2012.

53 PAUWELYN, Joost. Global Challenges at the intersection of trade, energy and the environment. Genebra: The Graduate Institute, Center for Trade and Economic Integration, 2010. p. 3-4. Disponível em: $<$ http://graduateinstitute.ch/ctei/publications_list/global.html> Acesso em 15 nov. 2012.

54 MARCEAU, Gabrielle. The WTO in the Emerging Energy Governance Debate. In: PAUWELYN, Joost. Global Challenges at the intersection of trade, energy and the environment. Genebra: The Graduate Institute, Center for Trade and Economic Integration, 2010. p. 26. Disponível em: <http://graduateinstitute.ch/ctei/publications_
Não se pode evitar mencionar que o aspecto ambiental, compreendendo poluição, alterações climáticas e outros problemas decorrentes, deve também ser analisado pela OMC nesse tipo de comércio, principalmente em razão da utilização de fontes fósseis como base para a geração de energia.

O setor de energia é uma indústria de capital intensivo que exige investimentos significativos em infraestrutura. O Acordo TRIMS não lida com política de investimento por si só, e somente dispõe sobre a obrigação de tratamento nacional e proibição de restrições quantitativas em relação a determinadas medidas de investimento, tais como conteúdo local e requisitos relacionados à troca comercial. É proibido impor medidas de investimento que exigem as empresas a comprar uma determinada quantidade de mercadorias de origem nacional ou condicionar importações sobre o montante das exportações. ${ }^{55}$

Vale salientar que, há 60 anos, a demanda por energia era uma fração do que é hoje, e da mesma forma os preços praticados. Por isso a liberalização da energia não foi uma prioridade para os países na celebração do GATT/1947. Além disso, a energia sempre foi um monopólio estatal e o comércio internacional, quando existia, estava concentrado em poucas companhias multinacionais. ${ }^{56}$

Hoje, não vivemos mais sem energia, sendo considerada uma necessidade básica para a manutenção da sociedade e da vida das pessoas. Tanto é que existe uma crescente preocupação em relação ao tema, tendo sido inclusive discutido na conturbada Rodada Doha, pois se tornou um elemento importante do comércio internacional.

Inclusive, existe o questionamento do enfraquecimento do órgão multilateral em face dos blocos regionais, tema que objeto de discussão na própria $\mathrm{OMC}^{57}$, mas que poderá ser objeto de outro estudo com maior aprofundamento.

list/global.html> Acesso em: 15 nov. 2012.

55 SELIVANOVA, Yulia. The WTO and energy wto rules and agreements of relevance to the Energy Sector. International Centre for Trade and Sustainable Development - ICTSD. Disponível em: < http://ictsd. org/downloads/2008/05/the20wto20and20energy.pdf $>$. Acesso em: 24 out. 2011.

56 COTTIER, Thomas et al. Energy in WTO law and policy. World Trade Organization. p. 1. Disponível em: <http://www.wto.org/ english/res_e/publications_e/wtr10_forum_e/wtr10_7may10_e. pdf $>$. Acesso em: 24 abr. 2011.

57 WORLD TRADE ORGANIZATION. Disponível em: <http://www.wto.org/english/forums_e/public_forum12_e/ 
Diante desse contexto, é possível visualizar alguns desafios que merecem atenção no âmbito da OMC, tais como:

Unificação da regulamentação do tema da energia para promover condições de competição igualitária e justa entre os diversos setores, quais sejam, combustíveis fósseis e não fósseis; energia incluindo óleo, gás, térmica, madeira, eletricidade e energia atômica; fontes de energia renovável para geração de energia elétrica (solar, eólica, ondas e marés) e biocombustíveis, ${ }^{58}$

Reforma da classificação dos serviços de energia, evitando que, por exemplo, transporte de óleo combustível seja classificado na categoria de serviços de transporte; ${ }^{59}$

A questão dos subsídios concedidos por países nos casos de energia renovável, como, por exemplo, os Estados Unidos no tratamento favorecido à produção de milho para produção de etanol, abordando o Art. XX, b, do GATT; ${ }^{60}$

O controle de produção versus a restrição de exportação, que pode ser visualizado no contexto do petróleo, em que países membros da OPEP desejam manter sua prática comercial sob o regulamento específico, e não desejam aplicar o Art. XI do GATT, que proíbe as restrições quantitativas; ${ }^{61}$

A propriedade industrial de tecnologias de produção, armazenamento ou transmissão de energia, por meio de patentes, e pagamento de royalties é outro aspecto que provavelmente tornar-se-á tema de discussão na OMC.

Portanto, é possível identificar o entrelaçamento de inúmeros temas em torno da questão energética, que surge como o ponto em comum para uma nova perspectiva normativa no âmbito da OMC,

public_forum12_e.htm>. Acesso em 04 jun. 2012.

58 COTTIER, Thomas et al. Energy in WTO law and policy. World Trade Organization. p. 8. Disponível em: <http://www.wto.org/ english/res_e/publications_e/wtr10_forum_e/wtr10_7may10_e. pdf $>$. Acesso em: 24 abr. 2011.

59 COTTIER, Thomas et al. Energy in WTO law and policy. World Trade Organization. p. 9. Disponível em: <http://www.wto.org/ english/res_e/publications_e/wtr10_forum_e/wtr10_7may10_e. pdf>. Acesso em: 24 abr. 2011.

60 COTTIER, Thomas et al. Energy in WTO law and policy. World Trade Organization. p. 11. Disponível em: <http://www.wto.org/ english/res_e/publications_e/wtr10_forum_e/wtr10_7may10_e. pdf $>$. Acesso em: 24 abr. 2011.

61 COTTIER, Thomas et al. Energy in WTO law and policy. World Trade Organization. p. 16. Disponível em: <http://www.wto.org/ english/res_e/publications_e/wtr10_forum_e/wtr10_7may10_e. pdf>. Acesso em: 24 abr. 2011. principalmente em função de ser um elemento potencial de conflitos entre países.

A importância da energia para o comércio se reflete no volume que ele representa. Apesar da relevância, a OMC trata o setor igual a qualquer outro, sem distinção. O comércio de serviços é consideravelmente menos liberalizado que o comércio de bens, dadas as peculiaridades das operações de serviços transfronteiriços. Reitera-se que inexiste entendimento pacífico de como a eletricidade deve ser negociada, se deve ser classificada como um bem ou um serviço. ${ }^{62}$

Uma transição da energia fóssil para renovável aumentará a importância das redes elétricas, que deverá ser usada para distâncias mais longas. Isso é mais um argumento para a criação de um comércio multilateral específico de energia. Nesse panorama, questiona-se se a OMC é o fórum adequado para criar um acordo-quadro sobre o comércio de energia? Ou seria mais viável adicionar disposições relacionadas com a energia nas regras atuais da OMC, o que evitaria o complexo processo de ratificação de um novo acordo internacional? Embora a OMC não discrimine energia, ela permite abordar algumas questões já tratadas nesse estudo, principalmente em relação à conservação dos recursos naturais, a proteção do meio ambiente, da saúde humana, animal ou vegetal, como exceção à regra geral. ${ }^{63}$

O ex-diretor da OMC Sr. Pascal Lamy afirmou que a organização mediante suas regras, transparência, comitês de discussão e seu mecanismo de rule-oriented pode e deve contribuir para uma governança global de energia, mas que a contribuição da OMC poderia ser reforçada através de uma abordagem mais holística para a energia, que atinge o equilíbrio entre as necessidades dos países exportadores e importadores de energia. ${ }^{64}$

62 LEAL-ARCAS, Rafael; FILIS, Andrew. The fragmented governance of the global energy economy: a legal-institutional analysis. The Journal of World Energy Law \& Business, 2013. Disponível em: <http://jwelb.oxfordjournals.org/content/early/2013/07/19/ jwelb.jwt011.abstract>. p. 21.

63 LEAL-ARCAS, Rafael; FILIS, Andrew. The fragmented governance of the global energy economy: a legal-institutional analysis. The Journal of World Energy Law \& Business, 2013. Disponível em: <http://jwelb.oxfordjournals.org/content/early/2013/07/19/ jwelb.jwt011.abstract>. p. 21.

64 ORGANIZAÇÃO MUNDIAL DO COMÉRCIO. Lamy calls for dialogue on trade and energy in the WTO. 2013. Disponivel em: <http://www.wto.org/english/news_e/sppl_e/sppl279_e.htm>. Acesso em: 14 nov. 2013. 
Ele ainda salientou que a OMC oferece aos seus membros a oportunidade única de se envolver em um diálogo para o futuro sobre a rápida expansão de uma interface entre energia e comércio. Isso pode ser útil para ajudar a traçar um caminho comum rumo a um maior apoio mútuo e coerente entre o comércio e os objetivos de política energética. Considerou que essa complementaridade e coerência são características essenciais de um sistema de governança global de energia eficiente e eficaz. ${ }^{65}$

Apesar das declarações otimistas - e políticas —, o que é salutar, no caso, o sistema geral da OMC não fornece uma governança global de energia suficiente. Além disso, as regras da OMC carecem de especificidade, tratando o comércio de energia de forma igual a bens e serviços. Uma solução seria discutir o tema já na Rodada de Doha, iniciada em 2001, mas que precisa do consenso de todos os membros para aprovar qualquer aditivo contratual. ${ }^{66}$

Outra possibilidade seria desenvolver um acordo plurilateral de comércio (Plurilateral Trade Agreements), que poderia fazer parte do Tratado da OMC ao ser adicionado ao anexo 4 do Acordo da OMC. Conforme artigo II.3 do Acordo OMC, tais acordos plurilaterais fazem parte do Acordo da OMC somente para os membros que as aceitaram. No entanto, os acordos plurilaterais não criam obrigações nem direitos para os membros que não as aceitaram.

Conforme artigo X.9 do Acordo da OMC, a Conferência Ministerial, mediante requerimento dos membros, pode acrescentar ou deletar um acordo ao Anexo 4, por consenso; e conforme artigo X.10, aditivos a esse acordo plurilateral deverão ser negociados conforme a previsão no próprio acordo plurilateral.

$\mathrm{O}$ acordo plurilateral pode ser considerado como uma obrigação WTO-plus, ou seja, se comprometer além do mínimo necessário que se exige para ser membro. Dois acordos plurilaterais de comércio foram implementados e tem sido efetivos para a redução de barreiras, como o

65 ORGANIZAÇÃO MUNDIAL DO COMÉRCIO. Lamy calls for dialogue on trade and energy in the WTO. 2013. Disponível em: <http://www.wto.org/english/news_e/sppl_e/sppl279_e.htm>. Acesso em: 14 nov. 2013.

66 BACCHUS, James. A way forward for the WTO. International Centre for Trade and Sustainable Development - ICTSD. Disponível em: < http://ictsd.org/downloads/2012/02/james-bacchus-a-wayforward-for-the-wto.pdf $>$. Acesso em: 10 out. 2013. de compras governamentais (GPA) e o de tecnologia da informação (ITA) da OMC. ${ }^{6}$

De certa forma, os acordos plurilaterais são positivos no sentido de que eles podem ser aderidos por todos os outros membros da OMC, a qualquer tempo. A não adesão não vincula quaisquer membros. $\mathrm{E}$ isso torna a organização mais flexível e torna um fórum muito mais eficaz para tratar de temas, como energia sustentável, ligados ao comércio mas que não estão sendo adequadamente cobertos pelas regras atuais, e não faz parte, ou não suficientemente parte, da agenda de negociações da Rodada Doha. ${ }^{68}$

Para exemplificar, seguem alguns temas urgentes de interesse comercial internacional que poderiam ser objeto de acordos plurilaterais adicionais: investimento, concorrência, energia verde, comércio digital, práticas cambiais, serviços, propriedade intelectual, harmonização regulatória, normas e regulamentações técnicas, facilitação do comércio, segurança do produto.

E se surgirem conflitos em decorrência desses acordos, deve-se aplicar o DSU? Absolutamente, pois essa seria uma grande vantagem em conceber um acordo dentro da estrutura jurídica da OMC, a exemplo dos acordos GPA e ITA. Caso contrário, à todo acordo celebrado fora do escopo da OMC teria que se criar todo um sistema novo de solução de controvérsias. Portanto, essa é uma oportunidade de criar um Sustainable Energy Trade Agreement para eliminar barreiras ao comércio e investimento das novas tecnologias da economia verde, no intuito de promover um desenvolvimento sustentável.

A agenda de negociações da OMC é sempre determinada pelos seus membros, com base em suas prioridades políticas e econômicas. Uma vez que se atinge um consenso numa agenda, as negociações podem iniciar. E essa regra se aplica também para o comércio de energia, que, apesar de estar longe de ter um acordo específico, o tema aparece nas negociações de Doha lançadas em 2001. ${ }^{69}$

67 BACCHUS, James. A Way Forward for the WTO. International Centre for Trade and Sustainable Development-ICTSD. Disponível em: <http://ictsd.org/downloads/2012/02/james-bacchus-a-wayforward-for-the-wto.pdf $>$. Acesso em: 10 out. 2013..

68 BACCHUS, James. A Way Forward for the WTO. International Centre for Trade and Sustainable Development - ICTSD. Disponível em: <http://ictsd.org/downloads/2012/02/james-bacchus-a-wayforward-for-the-wto.pdf $>$. Acesso em: 10 out. 2013.

69 ORGANIZAÇÃO MUNCIAL DO COMÉRCIO. Doba Round will benefit energy trade: Lamy. 2007. Disponível em: <http:// www.wto.org/english/news_e/sppl_e/sppl80_e.htm>. Acesso em: 
Isso se deve ao fato que a energia não foi devidamente abordada na Rodada Uruguai, aliás, jamais foi prioridade desde o GATT, em 1947. Como resultado, os membros da OMC assumiram compromissos limitados para abrir seus mercados aos operadores estrangeiros nos serviços de energia, como os serviços relacionados com a extração de petróleo e gás, serviços relacionados com a distribuição de gás e eletricidade e transporte de combustíveis por dutos.

A primeira área na agenda de Doha em que se trata de energia está nas negociações de serviços. Pela primeira vez os membros estão discutindo a energia como um setor de serviços específicos, cobrindo uma ampla gama de atividades relevantes para as empresas de energia e abrangendo todas as fontes de energia, incluindo as energias renováveis. Compromissos são procurados em atividades como a perfuração, engenharia, testes e análises técnicas, trabalhos de construção de gasodutos de curta e longa distância, e serviços de comércio por atacado e varejo de combustíveis.

A segunda área relevante da Rodada de Doha se relaciona com tecnologia limpa, visando abrir os mercados para bens e serviços ambientais, facilitando a promoção da eficiência energética, matéria prima para a produção de energia renovável, gestão de aquecimento e controle de poluição. Os equipamentos para geração de energia renovável incluem turbinas eólicas, painéis solares, sensores de energia geotérmica, células de combustível e medidores de energia elétrica. Os serviços ambientais incluem as negociações sobre serviços para reduzir GEE e melhorar a qualidade do ar, serviços de proteção da natureza ou serviços para a reabilitação de sítios de mineração.

A terceira área trata de facilitação de comércio, mediante negociação nos temas de melhorias e esclarecimentos ao trânsito de energia, obrigação contida nas regras do GATT/1947 que obrigam os membros permitir a passagem de mercadorias em trânsito por meio de seus territórios. Na atual Rodada de Doha, as propostas foram apresentadas para esclarecer

14 nov. 2013.

70 ORGANIZAÇÃO MUNCIAL DO COMÉRCIO. Doba Round will benefit energy trade: Lamy. 2007. Disponível em: <http:// www.wto.org/english/news_e/sppl_e/sppl80_e.htm>. Acesso em: 14 nov. 2013.

71 ORGANIZAÇÃO MUNCIAL DO COMÉRCIO. Doha Round will benefit energy trade: Lamy. 2007. Disponível em: < http:// www.wto.org/english/news_e/sppl_e/sppl80_e.htm>. Acesso em: 14 nov. 2013. o significado dessa obrigação e se inclui as instalações fixas, tais como gasodutos e oleodutos. ${ }^{72}$

Propostas sobre os impostos de exportação e subsídios de energia devem ser objeto de discussão, focando para as restrições à exportação de bens energéticos e outras matérias primas, porque essas restrições são mais predominantes nessa área do que no comércio em geral, além de preocupar os países importadores dependentes dos insumos. A questão dos subsídios na forma de produtos de energia de baixo preço, especialmente o gás natural, tem recorrentemente agitado os debates entre os membros da OMC e também faz parte das negociações em curso. ${ }^{73}$

No caso, o gás natural abaixo do preço praticado, ou mais barato que o praticado no âmbito internacional, estaria funcionando como uma espécie de vantagem comparativa, cujos efeitos se alastram para todos os produtos que utilizam esses recursos, desequilibrando o comércio internacional, afetando mais precisamente a concorrência.

Por fim, os biocombustíveis deveriam ser regulados de forma específica (vide caso DS 443 - biodiesel - promovido pela Argentina contra UE e Espanha) por permitir enfrentar a mudança climática, segurança energética e desenvolvimento rural. A delicadeza nesse tema se deve ao fato que acaba se inserindo em negociações sobre agricultura, para redução de tarifas e subsídios, setor considerado sempre como prioridade para a UE e EUA.

\section{Conclusão}

O que se verifica é que inexiste uma classificação abrangente e universalmente aceita de serviços de energia, incluindo serviços de energia sustentável na OMC. Negociações para a liberalização desses serviços vão envolver diversos setores, como engenharia, construção, manutenção e consultoria, podendo levar a distorções na abordagem. Atualmente, negociações de serviços têm progredido de forma lenta. Questões que estavam originalmente na mesa de negociações, como investimento, política de concorrência e transparência 72 ORGANIZAÇÃO MUNCIAL DO COMÉRCIO. Doha Round will benefit energy trade: Lamy. 2007. Disponível em: <http:// www.wto.org/english/news_e/sppl_e/sppl80_e.htm>. Acesso em: 14 nov. 2013.

73 ORGANIZAÇÃO MUNCIAL DO COMÉRCIO. Doba Round will benefit energy trade: Lamy. 2007. Disponível em: <http:// www.wto.org/english/news_e/sppl_e/sppl80_e.htm>. Acesso em: 16 nov. 2013. 
nas compras governamentais foram retiradas da agenda de negociações da Rodada de Doha, pela falta de um "consenso explícito" na Conferência Ministerial da OMC em Cancun, em 2003. ${ }^{74}$

A Rodada de Doha como um todo está praticamente estagnada, depois de uma falta de acordo em uma série de áreas críticas, tais como acesso a mercados não agrícolas (NAMA), ou seja, bens manufaturados. O sistema de single-undertaking da OMC, em que nada está acordado até que tudo esteja acordado, torna difícil nas atuais circunstâncias tratar de questões relacionadas com energia como parte de um conjunto amplo e abrangente de negociações comerciais multilaterais. ${ }^{75}$

A conduta recente da Índia em se opor à adoção do Pacote de Bali, de dezembro de 2013, para facilitação de

74 ICTSD. Fostering Low Carbon Growth: the case for a sustainable energy trade agreement. Disponível em: < http://ictsd.org/ downloads/2012/05/ fostering-low-carbon-growth-the-case-for-asustainable-energy-trade-agreement1.pdf> Acesso em: 13 nov. 2013.

75 ICTSD. Fostering Low Carbon Growth: the case for a sustainable energy trade agreement. Disponível em: <http://ictsd.org/ downloads/2012/05/ fostering-low-carbon-growth-the-case-for-asustainable-energy-trade-agreement1.pdf > Acesso em: 13 nov. 2013. comércio, alegando a necessidade de armazenamento de alimentos face à segurança alimentar, demonstra uma desvantagem do sistema de consenso. Recentemente, EUA e Índia estabeleceram um acordo com o compromisso que não haverá disputas referentes ao subsídio doméstico para venda de alimentos até que seja o tema amplamente discutido. ${ }^{76}$

Portanto, as normas da OMC poderiam ser revistas e atualizadas, mas as iniciativas são obstaculizadas pela regra do consenso. Um Acordo Plurilateral de Energia tende a ser um caminho viável para facilitar e acelerar os fluxos de energia, primeiro, por facultar a adesão dos interessados membros da própria organização multilateral, evitando longas negociações num tema de extrema sensibilidade. Segundo, por estabelecer um marco regulatório atualizado e acessível, que possa servir como base para geração de energia por meio sustentável.

76 NEW YORK TIMES. U.S. India Agreement on Stockpiles of Food Revives a Trade Deal. Disponível em: <http://www.nytimes. com/2014/11/14/business/international/us-india-agreement-clearsway-for-global-trade-deal.html?_r=0>. Acesso em: 17 nov. 2014. 


\section{Referências}

ALVAREZ, José E. The public international law regime governing international investment. The Hague: Brill Nijhoff, 2011.

AMARALJÚNIOR, Alberto do. A solução de controvérsias na OMC. São Paulo: Atlas, 2007.

ARIBOGAN, D U; BILGIN, M. New Energy Order Politics Neopolitics: From Geopolitics to Energeopolitics. Uluslar, Iliskiler, v. 5, n. 20, p. 109-131, 2009.

BACCHUS, James. A way forward for the WTO. International Centre for Trade and Sustainable Development - ICTSD. Disponível em: <http://ictsd.org/ downloads/2012/02/james-bacchus-a-way-forwardfor-the-wto.pdf.> Acesso em: 10 out. 2013.

BARNETT, Michael; FINNEMORE, Martha. Rules for the world: international organizations in global politics. London: Cornell University Press, 2004.

BARRAL, Welber de Oliveira (Org.). O Brasil e a Organização Mundial do Comércio. 2. ed. Curitiba: Juruá, 2002.

BHATTACHARYYA, Subhes C. Energy access programmes and sustainable development: a critical review and analysis. Energy for Sustainable Development, v. 16, n. 3, p. 260-271, 2012. Disponível em: <http://linkinghub.elsevier.com/retrieve/pii/ S0973082612000245>. Acesso em: 14 out. 2013.

BHATTACHARYYA, Subhes C. Financing energy access and off-grid electrification: a review of status, options and challenges. Renewable and Sustainable Energy Reviews, v. 20, n. 0, p. 462-472, 2013. Disponível em: $<$ http://www.sciencedirect.com/science/article/pii/ S1364032112007046>.

BHATTACHARYYA, Subkes C. Energy Economics. Part 1. London: Springer-Verlag Limited, 2011.

BOSSCHE, Peter Van Den. The law and policy of the world trade organization: text, cases and materials. 2 ed. Cambridge: Cambridge University Press, 2010.

BOSSELMAN, Fred et al. Energy, economics and the Environment: cases and Materials. December 21, 2008.
Foundation Press, 2006. Disponível em: <http://ssrn. com/abstract $=1319022>$. Acesso em: 07 out. 2012.

BRASIL. Decreto n. 7030/2009. Convenção de Viena sobre Direito dos Tratados. Disponível em: <http://www2. mre.gov.br/dai/dtrat.htm>. Acesso em: 10 abr. 2012.

BRITISH PETROLEUM. Statistical Review of World Energy. June 2012. Disponível em: <http:// www.bp.com/content/dam/bp/pdf/StatisticalReview-2012/statistical_review_of_world_ energy_2012.pdf>. Acesso em: 26 jul. 2013.

BURNS, Thaddeus J. The liberalization of environmental goods and services (EGS) trade and the need for a distinct EGS agreement. In: PAUWELYN, Joost. Global Challenges at the intersection of trade, energy and the environment. Genebra: The Graduate Institute, Center for Trade and Economic Integration, 2010. Disponível em: $\quad<$ http://graduateinstitute.ch/ctei/publications_ list/global.html> Acesso em: 15 nov. 2012.

BUSSE, Matthias; GRÖNING, Steffen. The resource curse revisited: governance and natural resources. Public Choice, Germany, v. 154, n. 1-2, p. 1-20, may/jul. 2013.

COELHO, Suani T; GOLDEMBERG, José. Energy access: Lessons learned in Brazil and perspectives for replication in other developing countries. Energy Policy, v. 61, n. 0, p. 1088-1096, 2013. Disponível em: <http://www.sciencedirect.com/science/article/pii/ S030142151300414X>.

COTTIER, Thomas et al. Energy in WTO law and policy. Disponível em: <http://www.wto.org/ english/res_e/publications_e/wtr10_forum_e/ wtr10_7may10_e.pdf>. Acesso em: 24 abr. 2011.

ENERGY CHARTER TREATY. Investor-State disputes. Disponível em: <http://www.encharter.org/index. php?id=213>. Acesso em: 01 fev. 2014.

ENERGY CHARTER TREATY. The energy charter treaty and related documents: a legal framework for international energy cooperation. Disponível em: $<$ http://www.encharter.org/fileadmin/user_upload/ document/EN.pdf>. Acesso em: 10 jan. 2013.

FATOUROS, Arghyrios A. An international legal framework for energy, collected courses of The Hague Academy 
of International Law. The Hague: Martinus Nijhoff Publishers, p. 355-446, 2008. v. 332.

FERREIRA, Lier Pires. Direito internacional, petróleo e desenvolvimento: políticas de produção petrolífera em áreas inativas com acumulações marginais. São Paulo: Saraiva, 2011.

FIORILLO, Celso Antônio Pacheco; FERREIRA, Renata Marques. Curso de direito da energia: tutela jurídica da água, do petróleo, do biocombustível, dos combustíveis nucleares e do vento. 2 ed. São Paulo: Saraiva, 2010.

GOLDTHAU, Andreas; WITTE, Jan Martin. Global Energy Governance: the new rules of the game. Washington: Brooking Press, 2010.

GUZMAN, Andrew T. Why LDCs sign treaties that hurt them: explaining the popularity of bilateral investment treaties. Journal of International Law, Virginia, v.38, n. 639, p. 639-688, jan. 1998.

GUZMAN, Andrew T.; PAUWELYN, Joost H. B. International trade law. New York: Wolters Kluwer-Aspen Publishers, 2009.

HOBÉR, Kaj. Investment Arbitration and the Energy Charter Treaty. Journal of International Dispute Settlement, Oxford, v. 1 , n. 1 , p. 153-190, 2010.

ICTSD. Aževêdo Extends WTO Negotiating Deadline in Bid to Secure Bali Deal. 2013. Disponível em: <http://ictsd. org/i/news/bridgesweekly/178924/\#sthash.sx4cqiV9. dpuf $>$. Acesso em: 14 nov. 2013.

ICTSD. Fostering Low Carbon Growth: the case for a sustainable energy trade agreement. Disponível em: http://ictsd.org/downloads/2012/05/fostering-lowcarbon-growth-the-case-for-a-sustainable-energytrade-agreement1.pdf Acesso em: 13 nov. 2013.

\section{INTERNATIONAL RENEWABLE ENERGY} AGENCY - IRENA. Members. Disponível em: <http:// www.irena.org/menu/index.aspx?mnu=cat\&PriMenu $\mathrm{ID}=46 \&$ CatID=67>. Acesso em: 13 nov. 2013.

INTERNATIONAL RENEWABLE ENERGY AGENCY - IRENA. Statute. Disponível em: <http:// www.irena.org/documents/uploadDocuments/ Statute/IRENA_FC_Statute_signed_in_
Bonn_26_01_2009_incl_declaration_on_further_ authentic_versions.pdf $>$. Acesso em: 13 nov. 2013.

KARNS, Margaret P.; MINGST, Karen A. International organizations: the politics and processes of global governance. 2 ed. Boulder: Lynne Rienner Publishers, 2010.

KHATIB, Hisham. IEA World Energy Outlook 2011-A comment. Energy Policy, v. 48, p. 737-743, 2012. Disponível em: <http://linkinghub.elsevier. com/retrieve/pii/S0301421512005149>. Acesso em: 26 maio 2013.

KONOPLYANIK, Andrei; WALDE, Thomas. Energy Charter Treaty and its Role in International Energy. Journal of Energy \& Natural Resources Law, v. 24, n. 4, p. 523-558, 2006.

KOSKENNIEMI, Martti; LEINO, Päivi. Fragmentation of International Law? Postmodern Anxieties. Leiden Journal of International Law, p. 553-579, 2002, Kluwer Law International.

LAFER, Celso. A OMC e a regulamentação do comércio internacional: uma visão brasileira. Porto Alegre: Livraria do Advogado, 1998.

LAMY, Pascal, Global Governance: From Theory to Practice, Journal of International Economic Law, v. 15, n. 3, p. 721-728, 2012.

LEAL-ARCAS, Rafael; FILIS, Andrew. The fragmented governance of the global energy economy: a legal-institutional analysis. The Journal of World Energy Law \& Business, 2013. Disponível em: <http://jwelb. oxfordjournals.org/content/early/2013/07/19/jwelb. jwt011.abstract>.

LYSTER, Rosemary; BRADBROOK, Adrian. Energy Law and Environment. Cambridge: Cambridge University Press, 2006.

MARCEAU, Gabrielle. The WTO in the Emerging Energy Governance Debate. In: PAUWELYN, Joost. Global Challenges at the intersection of trade, energy and the environment. Genebra: The Graduate Institute, Center for Trade and Economic Integration, 2010. p. 25. Disponível em: <http://graduateinstitute.ch/ctei/publications_list/ global.html> Acesso em: 15 nov. 2012. 
MELLO, Celso Duvivier de Albuquerque. Direito Internacional Econômico. Rio de Janeiro: Renovar, 1993.

MOROSINI, Fábio Costa. Globalização e novas tendências em filosofia do direito internacional: a dicotomia entre público e privado na cláusula de estabilização. In: MARQUES, Claudia Lima; ARAÚJO, Nadia de (Org.). O novo direito internacional: estudos em homenagem a Erik Jayme. Rio de Janeiro: Renovar, 2005. p. 549-572.

MOROSINI, Fábio Costa. Repensando estratégias regulatórias internacionais: a interação entre o setor elétrico e o meio ambiente na América do Norte. In: GUERRA, Sidney; FERREIRA JUNIOR, Lier Pires. $O$ direito internacional ambiental e do petróleo. Rio de Janeiro: Lumen Juris, 2009. p. 111-138.

MOROSINI, Fábio Costa; Gabrielle Marceau. The status of sustainable development in the law of the World Trade Organization. p. 59-92. In: CELLI JUNIOR, Umberto; BASSO, Maristela; AMARAL JUNIOR, Alberto do. (Coord.). Arbitragem e comércio internacional: estudos em homenagem a Luiz Olavo Baptista. São Paulo: Quartier Latin, 2013.

NAPPERT, Sophie; ORTINO, Federico. International resolution of energy trade and investment dispute. In: SELIVANOVA, Yulia (Org.). Regulation of energy in international trade law: WTO, nafta and energy charter. Kluwer Law International: 2011.

NEW YORK TIMES. U.S.-India Agreement on Stockpiles of Food Revives a Trade Deal. Disponível em: <http://www. nytimes.com/2014/11/14/business/international/ us-india-agreement-clears-way-for-global-trade-deal. html?_r=0>. Acesso em: 17 nov. 2014.

\section{ORGANIZAÇÃO DAS NAÇÕES UNIDAS.} Comissão Brundtland "Nosso Futuro Comum". Disponível em: <http://www.onu.org.br/a-onu-em-acao/a-onu-eo-meio-ambiente/>. Acesso em: 05 out. 2012.

ORGANIZAÇÃO MUNDIAL DO COMÉRCIO. Decisão Painel DS-426. Disponível em: <http://www. wto.org/english/tratop_e/dispu_e/cases_e/ds426_e. htm.> Acesso em 15 jan. 2013.

ORGANIZAÇÃO MUNDIAL DO COMÉRCIO. Disponível em: <http://www.wto.org/english/ forums_e/public_forum12_e/public_forum12_e. htm>. Acesso em: 04 jun. 2012.

ORGANIZAÇÃO MUNDIAL DO COMÉRCIO. Disputes. Disponível em: <http://www.wto.org/english/ tratop_e/dispu_e/find_dispu_cases_e.htm\#results $>$. Acesso em: 10 nov. 2012.

ORGANIZAÇÃO MUNDIAL DO COMÉRCIO. Doba Round will benefitenergy trade: Lamy. 2007. Disponível em: <http://www.wto.org/english/news_e/sppl_e/ sppl80_e.htm>. Acesso em: 14 nov. 2013.

ORGANIZAÇÃO MUNDIAL DO COMÉRCIO. GATT/1994. Disponível em: <http://www.wto. org/english/res_e/booksp_e/analytic_index_e/ gatt1994_05_e.htm>. Acesso em: 10 nov. 2012.

ORGANIZAÇÃO MUNDIAL DO COMÉRCIO. Lamy calls for dialogue on trade and energy in the WTO. 2013. Disponível em: <http://www.wto.org/english/ news_e/sppl_e/sppl279_e.htm>. Acesso em: 14 nov. 2013.

ORGANIZAÇÃO MUNDIAL DO COMÉRCIO. World Trade Report 2010. Disponível em: <http://www. wto.org/english/res_e/publications_e/wtr10_e.htm>. Acesso em: 10 nov. 2012.

ORGANIZAÇÃO MUNDIAL DO COMÉRCIO. World Trade Report 2013. Disponível em: <http:// www.wto.org/english/res_e/booksp_e/world_trade_ report13_e.pdf>. Acesso em: 18 jul. 2013.

ORGANIZAÇÃO MUNDIAL DO COMÉRCIO. World Trade Report 2014. Disponível em: <http:// www.wto.org/english/res_e/booksp_e/world_trade_ report14_e.pdf $>$. Acesso em: 17 nov. 2014.

PACHAURI, Shonali. Reaching an international consensus on defining modern energy access. Current Opinion in Environmental Sustainability, v. 3, n. 4, p. 235240, 2011. Disponível em: <http://www.sciencedirect. com/science/article/pii/S1877343511000625>.

PACHAURI, Shonali; CHERP, Aleh. Energy security and energy access: distinct and interconnected challenges. Current Opinion in Environmental Sustainability, v. 3, n. 4, p. 199-201, 2011. Disponível em: <http:// www.sciencedirect.com/science/article/pii/ S1877343511000637>. 
PAUWELYN, Joost (Org.). Global Challenges at the intersection of trade, energy and the environment. Genebra: The Graduate Institute, Center for Trade and Economic Integration, 2010. p. 25. Disponível em: <http:// graduateinstitute.ch/ctei/publications_list/global. html> Acesso em: 15 nov. 2012.

PEAT, Daniel. The Perfect FIT: Lessons for Renewable Energy Subsidies in the World Trade Organization. LSU Journal of Energy Law and Resources. 2012. Disponível em: <http://ssrn.com/abstract=2128654>. Acesso em: 18 nov. 2012.

PEAT, Daniel. The Wrong Rules for the Right Energy: The WTO SCM Agreement and Subsidies for Renewable Energy. Environmental Law and Management. n. 3, 2012. p. 14-15. Disponível em: <http://ssrn. com/abstract=1998240 or http://dx.doi.org/10.2139/ ssrn.1998240>. Acesso em: 16 maio 2012.

PEREIRA, Ana Cristina Paulo (Org.). Direito internacional do comércio: mecanismo de solução de controvérsias e casos concretos na OMC. Rio de Janeiro: Lúmen Júris, 2003.

PETERSMANN, Ernst-Ulrich. Constitutional Problems of Multilevel Judicial Governance in Trade and Investment Regulation. March 1, 2012. EUI Working Papers LAW, n.2012/08. Available at SSRN: <http://ssrn. com/abstract $=2069916$ or http://dx.doi.org/10.2139/ ssrn.2069916>

PINTO JUNIOR, Helder Queiroz et al. Economia da energia: fundamentos econômicos, evolução histórica e organização industrial. Rio de Janeiro: Elsevier, 2007.

PRAZERES, Tatiana Lacerda. A OMC e os blocos regionais. São Paulo: Aduaneiras, 2008.

RUBINI, Luca. the subsidization of renewable energy in the WTO: issues and perspectives. Disponível em: $<$ http://papers.ssrn.com/sol3/papers.cfm?abstract $\underline{\mathrm{id}=1933863>}>$. Acesso em: 31 out. 2011.

SAKMAR, Susan L. Bringing energy trade into the WTO: the historical context, current status, and potential implications for the middle east region (2008), Indiana International \& Comparative Law Review, v. 18, n. 1, p. 89, 2008. Disponível em: <http://ssrn.com/ abstract $=1995896>$ Acesso em: 25 nov. 2011.
SELIVANOVA, Yulia (Org.). Challenges for multilateral energy trade regulation: WTO and Energy Charter. Disponível em: <http://papers.ssrn.com/sol3/papers. cfm?abstract_id=1632557>. Acesso em: 31 out. 2011.

SELIVANOVA, Yulia (Org.). Regulation of energy in international trade law: WTO, nafta and energy charter. Kluwer Law International: 2011.

SELIVANOVA, Yulia (Org.). The WTO and energy WTO rules and agreements of relevance to the Energy Sector. International Centre for Trade and Sustainable Development - ICTSD. Disponível em: <http://ictsd. org/downloads/2008/05/the20wto20and20energy. pdf> Acesso em: 24 out. 2011.

SHIH, Wen-chen. Energy Security, GATT / WTO and Regional Agreements. SIEL, n. 10. 2008. p. 41.

SIMPSON, Robin. Energy: sustainable access for all. Consumer Policy Review, v. 16, n. 2, p. 66-74, 2006. Disponível em: <http://search.ebscohost.com/login. aspx?direct $=$ true $\& d b=$ buh $\& A N=20847488 \&$ site $=$ eho st-live \&scope $=$ site $>$.

SUSSMAN, Edna. A multilateral energy sector investment treaty: is it time for a call for adoption by all nations? International Lawyer, v. 44, n. 3, p. 939, 2010. Disponível em: <http://go.galegroup.com/ps/i.do?id= GALE $\mid$ A $248263440 \& v=2.1 \& u=$ capes $58 \&$ it $=r \& p=A$ $\mathrm{ONE} \& \mathrm{sw}=\mathrm{w}>$.

TEIXEIRA, Anderson Vichinkeski. Teoria pluriversalista do direito internacional. São Paulo: WMF Martins Fontes, 2011.

THORSTENSEN, Vera. A OMC: Organização Mundial do Comércio e as negociações sobre investimentos e concorrência. Revista Brasileira de Política Internacional, Brasília, v. 1, n. 41, p. 57-89, 1998. p. 6970. Disponível em: <http://www.scielo.br/pdf/rbpi/ v41n1/v41n1a04>. Acesso em: 06 fev. 2014.

THORSTENSEN, Vera. Organização Mundial do Comércio: as regras do comércio internacional e a nova rodada de negociações multilaterais. 2. ed. São Paulo: Aduaneiras, 2001.

THORSTENSEN, Vera; et. al. A regulação do comércio internacional de energia: combustíveis e energia elétrica. São Paulo: FIESP, 2013. 
TRINDADE, Antônio Augusto Cançado. Direito das organizações internacionais. 5. ed. rev. atual e ampl. Belo Horizonte: Del Rey, 2012.

UNCTAD. World Investment Report 2014. Disponível em: $<$ http://unctad.org/en/PublicationsLibrary/wir2014_ overview_en.pdf $>$. Acesso em: 17 nov. 2014.

WORIKA, Ibibia L. Production, management, OPEC and the WTO. In: PAUWELYN, Joost. Global Challenges at the intersection of trade, energy and the environment. Genebra: The Graduate Institute, Center for Trade and Economic Integration, 2010. p. 87-93. Disponível em: $<$ http://graduateinstitute.ch/ctei/publications_list/ global.html> Acesso em: 15 nov. 2012.

YANOVICH, Alan. WTO rules and the energy sector. In: SELIVANOVA, Yulia (Org.). Regulation of energy in international trade law: wto, nafta and energy charter. Kluwer Law International: 2011. p. 1-48. 
Para publicar na Revista de Direito Internacional, acesse o endereço eletrônico www.rdi.uniceub.br ou www.brazilianjournal.org.

Observe as normas de publicação, para facilitar e agilizar o trabalho de edição. 